\title{
基于氟烷基自由基过程构建手性中心的研究进展
}

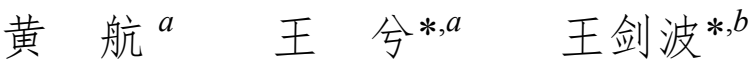 \\ ( ${ }^{a}$ 湖南大学化学化工学院 长沙 410082) \\ $\left({ }^{b}\right.$ 北京大学化学与分子工程学院 北京 100871)
}

\begin{abstract}
摘要 含氟的有机化合物被广泛地应用于制药、农业化学品、材料科学等多个领域. 三氟甲基、二氟甲基、全氟烷基 等是应用非常广泛的含氟官能团，因此发展普适高效的引入氟烷基的新方法具有重大意义. 氟烷基自由基反应近年来 已经发展成为引入氟烷基的有效方法. 另一方面，氟烷基取代的手性有机分子的合成也受到了人们的重点关注. 然而 由于氟烷基自由基的高反应活性, 其反应的选择性较难控制, 特别是关于对映选择性控制的报道不多, 更缺乏相关综 述予以总结. 综述了近二十年来基于氟烷基自由基过程的不对称合成方法的研究进展，对各反应的选择性、普适性、 反应机理等方面进行着重介绍. 本综述根据反应机理分为三部分：(1)经由氟烷基自由基的烯醇/烯胺中间体不对称氟烷 基化; (2)经由氟烷基自由基的烯烃不对称双官能团化; (3)经由氟烷基自由基的烯基硼酸酯酸根型复合物立体选择性 1,2-迁移.
\end{abstract}

关键词 氟烷基化、自由基、不对称合成、催化

\section{Research Developments of the Construction of Chiral Center Based on Fluoroalkyl Radical Reactions}

\author{
Huang, Hang ${ }^{a} \quad$ Wang, $\mathrm{Xi}^{*, a} \quad$ Wang, Jianbo*,b \\ ( ${ }^{a}$ College of Chemistry and Chemical Engineering, Hunan University, Changsha 410082) \\ ( ${ }^{b}$ College of Chemistry and Molecular Engineering, Peking University, Beijing 100871)
}

\begin{abstract}
Fluorine-containing organic compounds have been widely applied in various fields, such as pharmacy, agrochemicals, materials science, etc. Trifluoromethyl, difluoromethyl and perfluoroalkyl groups represent the typical fluorine-containing functional groups. Hence, the development of highly efficient methods for introducing fluoroalkyl groups is of primary importance. In recent years, the reactions based on fluoroalkyl radicals have been developed into competent methods for introducing fluoroalkyl groups. On the other hand, the synthesis of the chiral molecules containing fluoroalkyl groups has attracted considerable attentions. However, attributed to the high reactivity of the fluoroalkyl radicals, the control of the reaction selectivity is difficult. Particularly, so far there have been only limited reports on the enantiocontrol of the reaction in this regard and the corresponding review of the field still lacks. This review summarizes the research on the asymmetric synthesis based on fluoroalkyl radical reactions developed over the past 20 years. The review introduces the selectivities, scope and mechanism of various reactions. It is divided into three different parts according to the type of the reaction: (1) asymmetric fluoroalkylation of enol/enamine intermediate through fluoroalkyl radical, (2) asymmetric difunctionalization of olefin through fluoroalkyl radical, (3) stereoselective 1,2-shift of vinylboronate complexes through fluoroalkyl radical.
\end{abstract}

Keywords fluoroalkylation; radicals; asymmetric synthesis; catalysis

在制药工业、农业化学品产业以及功能材料领域中, 含氟的有机化合物非常常见. 据统计, 30\%以上的农业 化学品以及 $20 \%$ 以上的药物中至少含有一个氟原子. 在 功能材料中, 引入氟原子也可以改变材料的熔点、溶解
度、摩擦力、通透性、抗腐蚀能力、绝缘性能等. 氟原 子大小和氢原子接近, 且碳氟键非常稳定, 具有很强的 吸电子诱导效应. 将其引入有机分子将显著地改变分子 的偶极矩、酸性、脂溶性, 进而影响其代谢稳定性和生

\footnotetext{
* Corresponding authors. E-mail: cccewangxi@hnu.edu.cn; wangjb@pku.edu.cn

Received August 27, 2018; revised November 21, 2018; published online November 30, 2018.

Dedicated to Professor Qingyun Chen on the occasion of his 90th birthday.

Project supported by the National Natural Science Foundation of China (No. 21332002).

国家自然科学基金(No. 21332002)资助项目.
} 
物活性 ${ }^{[1]}$.

三氟甲基 $\left(\mathrm{CF}_{3}\right)$ 作为一个非常重要的含氟官能团, 其结构和反应性都与甲基有很大差别, 其含有三根稳定 的碳氟键, 具有非常强的吸电子诱导效应. 早在 1928 年, Lehmann ${ }^{[2]}$ 就发现具有生物活性的含有三氟甲基的 有机分子. 三氟甲基可以降低药物分子的电子云密度, 保护其不被细胞色素 P450 氧化酶氧化, 从而增加其代 谢稳定性. 另一方面, 因为氟的原子半径小, 不会导致 分子构象的很大改变. 因此在制药工业中, 经常用氟原 子取代氢原子以及三氟甲基取代甲基或氢, 以期获得活 性更优的分子. 另外, 全氟烷基 $\left(\mathrm{C}_{n} \mathrm{~F}_{2 n+1}\right)$ 也具有和三氟 甲基类似的性质和作用，其结构相对于相应的普通烷基 较刚性, 且可以很大程度地增加分子的脂溶性. 二氟甲 基 $\left(\mathrm{CF}_{2} \mathrm{H}\right)$ 除了具有三氟甲基的类似性质，还可以形成分 子间和分子内的氢键 ${ }^{[3]}$. 然而, 这些含氟官能团在自然 界中并不存在, 因此发展普适高效的引入方法在有机合 成中至关重要. 近年来, 氟烷基取代的手性分子也越来 越受到人们的关注. 图 1 中列举了一些含有氟烷基的手 性药物和手性农药活性分子.

构建含有三氟甲基和全氟烷基手性中心的研究进 展已经被马军安和 Cahard 等 $^{[4]}$ 总结. 另一方面, 三氟甲 基自由基和全氟烷基自由基的结构、性质、特点以及自 由基氟烷基化反应也在 Dolbier ${ }^{[5]}$ 和 Studer $^{[6]}$ 的综述中有 详细介绍. 2016 年, 吴劼等 ${ }^{[7]}$ 总结了近年来基于光致氧 化还原过程的自由基三氟甲基化和二氟甲基化反应. 最 近，刘国生等 ${ }^{[8]}$ 也对经由三氟甲基自由基的烯烃双官能 化反应进行了综述. 基于离子型反应构建氟烷基的手性 中心的报道包括对氟烷基取代潜手性底物(如醛、酮、 亚胺、半缩醛、半缩酮、腙等)的不对称亲核进攻以及 醛、酮的不对称亲核氟烷基化等. 此外还包括氟烷基取 代烯烃的不对称环丙烷化, 不对称氢化以及氟烷基取代 醛、酮的不对称羰基 ene 反应等策略，一般具有高效和 高选择性的特点. 基于氟烷基自由基过程构建手性中心 的反应则涉及氟烷基自由基对各种不饱和体系的加成, 在拓展了底物范围的基础上与其它非自由基反应形成 了互补. 然而自由基中间体具有寿命短和高活性的特 点, 反应的选择性控制具有挑战性, 很大程度限制了这 一领域的发展. 近年来, 利用辅基、有机小分子催化、 路易斯酸催化、过渡金属催化等策略, 经由氟烷基自由 基过程的手性中心的构建也取得了一些令人瞩目的进 展. 本综述旨在介绍近二十年来经由氟烷基自由基过程 构建手性中心的相关反应, 包括直接构建氟烷基取代的 手性中心, 以及构建碳或杂原子取代的手性中心. 本文 将从反应本身特点、底物普适性、反应机理等多个方面 进行详细介绍.<smiles>CCOCCOC(=O)Nc1ccc(Cl)cc1C</smiles>

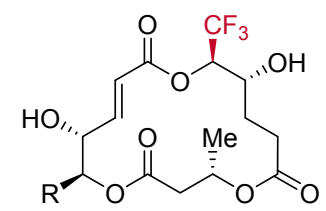

$$
\left(\mathrm{R}=\mathrm{Me}, \mathrm{CF}_{3}\right)
$$$$
\text { Anticancer agent }
$$<smiles>[X]C1(F)OC2OC(C)CCC3C(C)CCC(C31)C2(C)F</smiles>

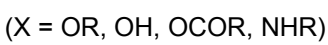

Fluoroatemisinin<smiles>CC(O)C(=O)Nc1cccc2c1C(=O)c1sccc1CS2(=O)=O</smiles>

KW-7158<smiles>CN(C)c1ccc([C@H]2C[C@]3(O)C(CCC3(C(F)(F)F)C(F)(F)F)C3CCC4=CC(=O)CCC4=C32)cc1</smiles>

Progesterone receptor antagonist<smiles>CC(=O)c1ccc([C@H]2CC3(C)C(CC[C@H]3O)C3CCC4=CC(=O)CCC4=C32)cc1</smiles>

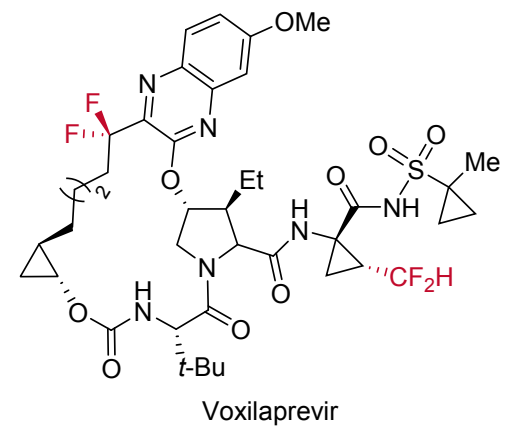

图 1 含有三氟甲基、全氟烷基、二氟甲基的手性生物活性分 子

Figure 1 Chiral bioactive molecules containing trifluoromethyl, perfluoroalkyl and difluoromethyl group

\section{1 三氟甲基自由基的介绍}

\section{1 三氟甲基自由基的结构与性质}

甲基自由基 $\left(\cdot \mathrm{CH}_{3}\right)$ 的平面正三角形结构在电子顺磁 共振(ESR)、红外(IR)、微波(MW)和分子轨道理论计算 等研究中得到了证实. 利用红外光谱和电子顺磁共振技 术分别对单氟、二氟、三氟取代甲基的研究表明，自由 基的构型会随氟取代基增多而发生递变，逐渐偏离甲基 自由基的平面结构，形成三角雉形。通过计算所得到的 三氟甲基自由基、二氟甲基自由基、单氟甲基自由基中 碳氟键与 $C_{3}$ 对称轴垂直平面的夹角 $\theta$ 分别为 $17.8^{\circ}$ 、 $12.7^{\circ}$ 、小于 $5^{\circ}$, 也说明存在这种趋势(图 2) ${ }^{[5,9]}$. 其原因 是, 氟的孤对电子占据轨道与碳的单电子占据 $p$ 轨道之 间的相互排斥作用会因为自由基结构从平面正三角形 变为三角雉形而减弱. 另一方面, 此过程中碳的单电子 
占据 $p$ 轨道与碳氟键的 $\sigma^{*}$ 反键轨道之间的相互作用加 强, 降低了碳原子中心的电子云密度, 同时增加了高电 负性氟原子的电子云密度而使自由基得到稳定 ${ }^{[6]}$. 三氟 甲基自由基也具有动力学稳定性. 与甲基自由基相比, 三氟甲基自由基外围被高电负性的氟原子包裹而具有 屏蔽效应, 此外, 碳氟键的键能很高 $(\mathrm{BDE}=115.7$ $\mathrm{kcal} / \mathrm{mol}$ ). 因此, 三氟甲基自由基的自身二聚和碳氟键 断裂的自由基转移这两种自身终止过程都需要较高的 活化能 ${ }^{[9]}$. 三氟甲基自由基具有较低的单电子占据轨道 (SOMO)能级, 亲电性强, 可以对一些不饱和体系, 如芳 烃、烯烃、炔烃、烯醇、烯胺、烯基硼酸酯酸根型复合 物、异腈等自由基加成.
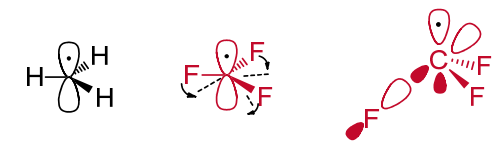

图 2 甲基自由基和三氟甲基自由基的结构对比

Figure 2 Structural comparison between methyl radical and trifluoromethyl radical

\section{2 氟烷基自由基的产生方式}

氟烷基化试剂如氟烷基碘化物、氟烷基磺酰氯以及 亲电性的三氟甲基三价碘试剂(Togni 试剂), 可以被还 原剂如富电子 $\pi$ 体系、还原态的光敏催化剂、低价态过 渡金属、锂试剂和硼酸酯形成的酸根型复合物等单电子 还原，产生相应的氟烷基自由基・ $\mathrm{R}_{\mathrm{f}}$ (Eq. 1$)^{[10]}$.

$$
\mathrm{R}-\mathrm{X} \stackrel{\text { SET reduction }}{\longrightarrow} \cdot \mathrm{R}
$$

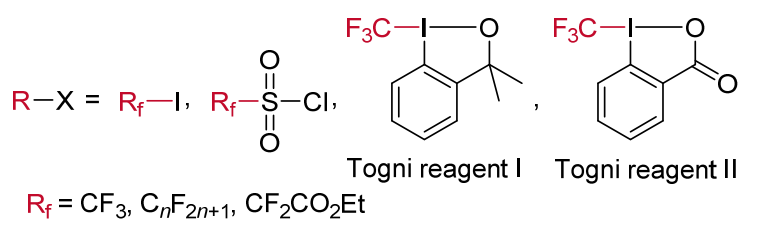

氟烷基自由基对双键加成产生烷基自由基中间体. 如何基于该高活性的中间体来构建手性中心是不对称 自由基氟烷基化反应的关键问题. 本文将介绍 Scheme 1 所示的三种策略：第一，氟烷基自由基对手性的烯醇负 离子或烯胺中间体加成, 再经由单电子氧化, 构建羰基 $\alpha$ 位的全氟烷基手性中心(Scheme 1a); 第二, 氟烷基自 由基对烯烃的加成, 利用手性配体配位的 $\mathrm{d}^{9}$ 结构的二价 铜与烷基自由基的相互作用形成手性三价铜中间体, 再接受亲核试剂进攻或亲核试剂在铜中心还原消除, 得 到不对称烯烃双官能团化的产物(Scheme 1b); 第三, 氟 烷基自由基对手性 $\mathrm{R}$ 基烯基硼酸酯的酸根型复合物加 成, 经由单电子氧化后, 促使 $\mathrm{R}$ 基团的 1,2-迁移构建碳 碳键, 形成新的手性中心(Scheme 1c).

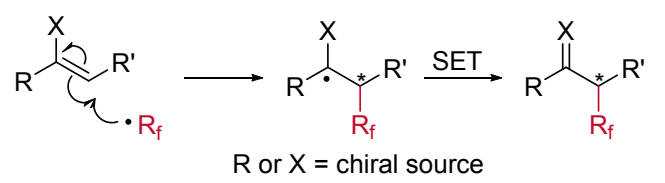<smiles>[R]C/C=C\CC[R]</smiles>

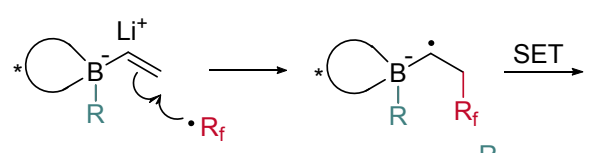<smiles>[R]CC([R])[B-]1([R])CCCCC1</smiles>

图式 1 经由氟烷基自由基构建手性中心的三种策略 Scheme 1 Three strategies for constructing chiral center through fluoroalkyl radical

\section{2 经由氟烷基自由基的烯醇/烯胺中间体不对 称氟烷基化}

\section{1 早期的自由基的不对称氟烷基化报道}

1993 到 1994 年, Iseki 和 Kobayashi 等 ${ }^{[11]}$ 实现了手性 辅基控制的 $N$-酰基惡唑啉酮羰基 $\alpha$ 位的非对映选择性 的三氟甲基化(Eq. 2). 底物 $\mathbf{1}$ 在二异丙基氨基锂(LDA) 的存在下篗取质子形成烯醇锂盐, 在三乙基硼和微量氧 气存在下产生的三氟甲基自由基对其进行立体专一性 地自由基加成生成 2 . 但该反应的非对映选择性不理想 $(86 \% d e)$.

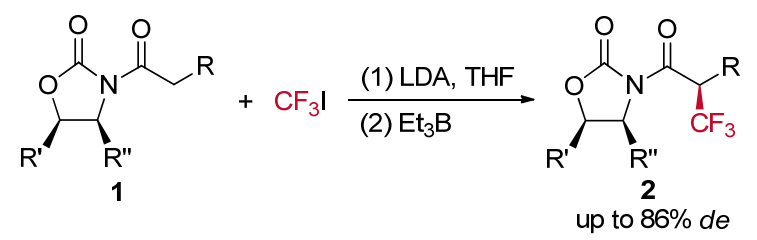

2006 年, Mikami 等 ${ }^{[12]}$ 使用烯醇硅醚 3 为底物, 在丁 基锂和手性配体 $(S, S)-(-)$-氢化苯偶姻 6 或鹰爪豆碱 7 的作用下形成烯醇锂盐 4 , 随后接受三氟甲基自由基的 加成, 得到 $\alpha$ 位三氟甲基取代的手性环己酮 5 . 但该转 化的效率和对映选择性均不高(Scheme 2).

\section{2 有机小分子催化的不对称自由基氟烷基化}

2009 年, MacMillan 课题组 ${ }^{[13]}$ 实现了基于光致氧化 还原过程的二级胺催化的醛基 $\alpha$ 位不对称氟烷基化 (Scheme 3). 各种醛 8 都可以高对映选择性地引入三氟 甲基、全氟烷基、各种取代的二氟甲基等含氟官能团，且 所使用的含氟碘代烷 9 相对廉价易得，反应的官能团耐 受性好，选择性高( $90 \% \sim 99 \% e e)$. 值得注意的是，无论 对于 $\beta$ 位为 $R$ 型还是 $S$ 型的手性醛底物, 在 11 和 12 


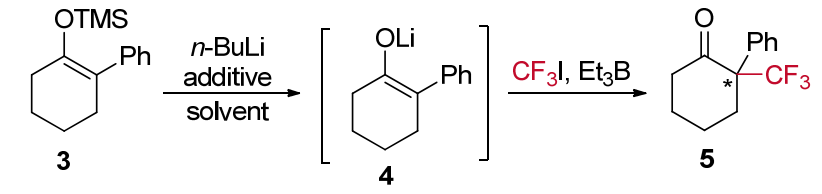

\begin{tabular}{cccc}
\hline \multicolumn{1}{c}{ Additive } & Solvent & Yield/\% & $e e / \%$ \\
\hline$(S, S)$-Hydrobenzoin (6) & $\mathrm{Et}_{2} \mathrm{O}$ & 39 & 27 \\
$(-)$-Sparteine (7) & $t$-BuOMe & 13 & -44 \\
\hline
\end{tabular}

图式 2 手性配体控制的烯醇锂盐的不对称三氟甲基化

Scheme 2 Chiral ligand controlled asymmetric trifluoromethylation of ketone lithium enolates

的共催化下, 都可以实现其 $\alpha$ 位的不对称三氟甲基化, 分别得到 anti 产物 13 和 syn 产物 14. 该反应的机理包 含光催化循环和有机小分子催化循环两个部分. 首先光 敏催化剂 11 在光照条件下达到激发态, 激发态的光敏 催化剂 ${ }^{*} \operatorname{Ir}(\mathrm{ppy})_{2}(\mathrm{dtb}-\mathrm{bpy})^{+}$具有强氧化性, 可以从催化量 的烯胺中获得一个电子, 得到光敏催化剂还原态 $\operatorname{Ir}(\text { ppy })_{2}(\mathrm{dtb}-b p y)\left(-1.51 \mathrm{~V}\right.$ vs SCE in $\left.\mathrm{CH}_{3} \mathrm{CN}\right)$. 三氟碘 甲烷被还原态的光敏催化剂单电子还原, 得到一个电 子, 生成三氟甲基自由基的同时再生光敏催化剂. 所产 生的三氟甲基自由基对手性二级胺催化剂 12 与醛底物 8 缩合产生的手性烯胺中间体 15 加成, 构建含三氟甲基 的手性中心, 得到自由基中间体 16, 该中间体可以还原 光敏催化剂生成亚胺盐正离子 17 , 最后经水解得到产 物 10, 并再生手性二级胺催化剂 12. 由于咪唑烷酮上叔 丁基位阻的影响, 使得手性烯胺中的 $4 \pi$ 电子体系处于 远离叔丁基的方向，而咪唑烷酮上的甲基则阻碍了 $R e$ 面的自由基加成, 使得自由基高选择地由 $S i$ 面加成, 实 现对反应对映选择性的控制.

2015 年, Melchiorre 等 ${ }^{[14]}$ 报道了室温下可见光驱动 结合相转移催化的 $\beta$-狮酮酸酯的不对称氟烷基化反应 (Scheme 4). 反应在金鸡纳碱衍生物 $\mathbf{2 0}$ 的相转移催化下 进行, 适用于各种给电子和吸电子取代的五元环 $\beta$-酮酸 酯高对映选择性地构建季碳中心. 推测的反应途径为: 首先 $\beta$-酮酸酯 18 失去质子后与相转移催化剂 20 形成含 有手性阳离子的烯醇式结构 21, 该烯醇式中间体可以 和氟烷基碘化物进一步形成电子给体一受体复合物 (EDA complex). 该复合物在可见光驱动下发生了由富 电子的烯醇阴离子到贫电子的氟烷基碘化物之间的 $\pi \rightarrow \sigma$ 单电子转移过程, 产生氟烷基自由基, 接着氟烷 基自由基对手性烯醇式中间体进行原子转移自由基加 成(ATRA), 经由自由基中间体 22 得到氟烷基碘代中间 体 23, 最后离去碘负离子得到最终产物 19. 作者观察到 当加入 $\beta$-䒢酮酸酯底物 18、相转移催化剂 20 以及碱形 成手性烯醇式中间体 21 时, 溶液呈现无色. 但加入氟烷 基碘化物后溶液呈现黄色, 并且吸收光谱出现了向可见
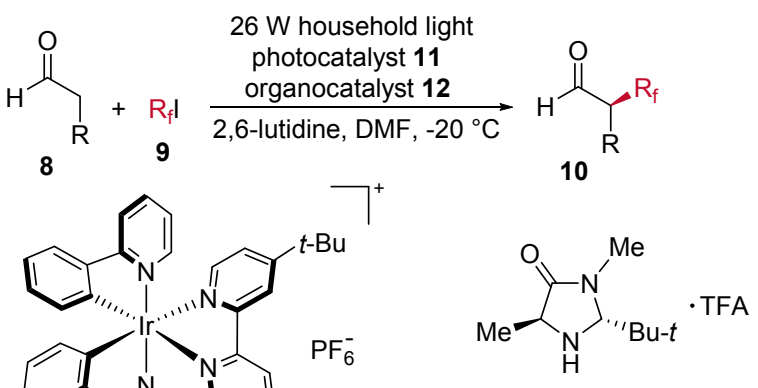

organocatalyst 12 photocatalyst 11<smiles>O=CC(c1ccccc1)C(F)(F)F</smiles>

$79 \%, 99 \%$ ee $\mathrm{O} \mathrm{Me}$ $\overbrace{\mathrm{Ph}}$

$\overline{\mathrm{C}} \mathrm{F}_{3}$

$14,62 \%, 99 \%$ ee,

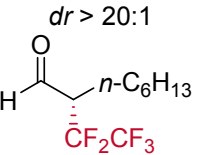

, 96\%

$-72 \%, 98 \%$ ee

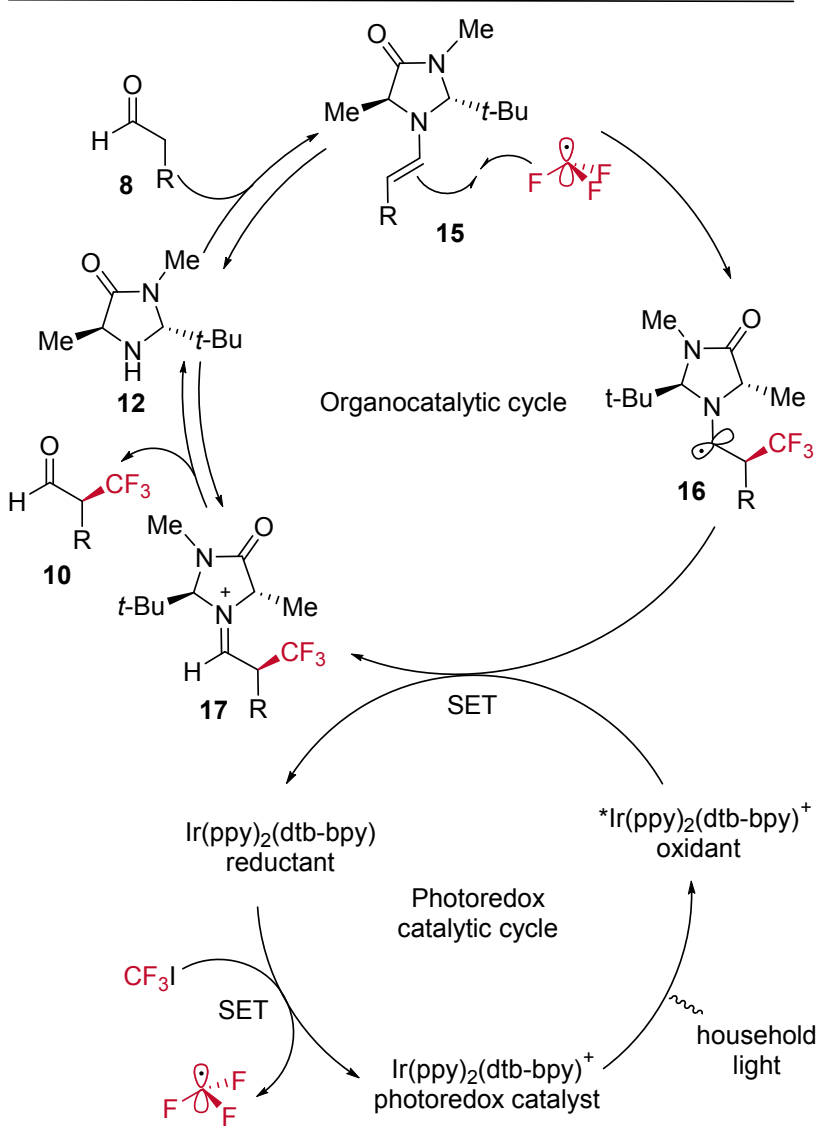

图式 3 可见光促进二级胺催化的醛的不对称三氟甲基化 Scheme 3 Visible light induced secondary amines catalyzed asymmetric trifluoromethylation of aldehydes 
光区的红移, 表明电子给体-受体复合物的存在.
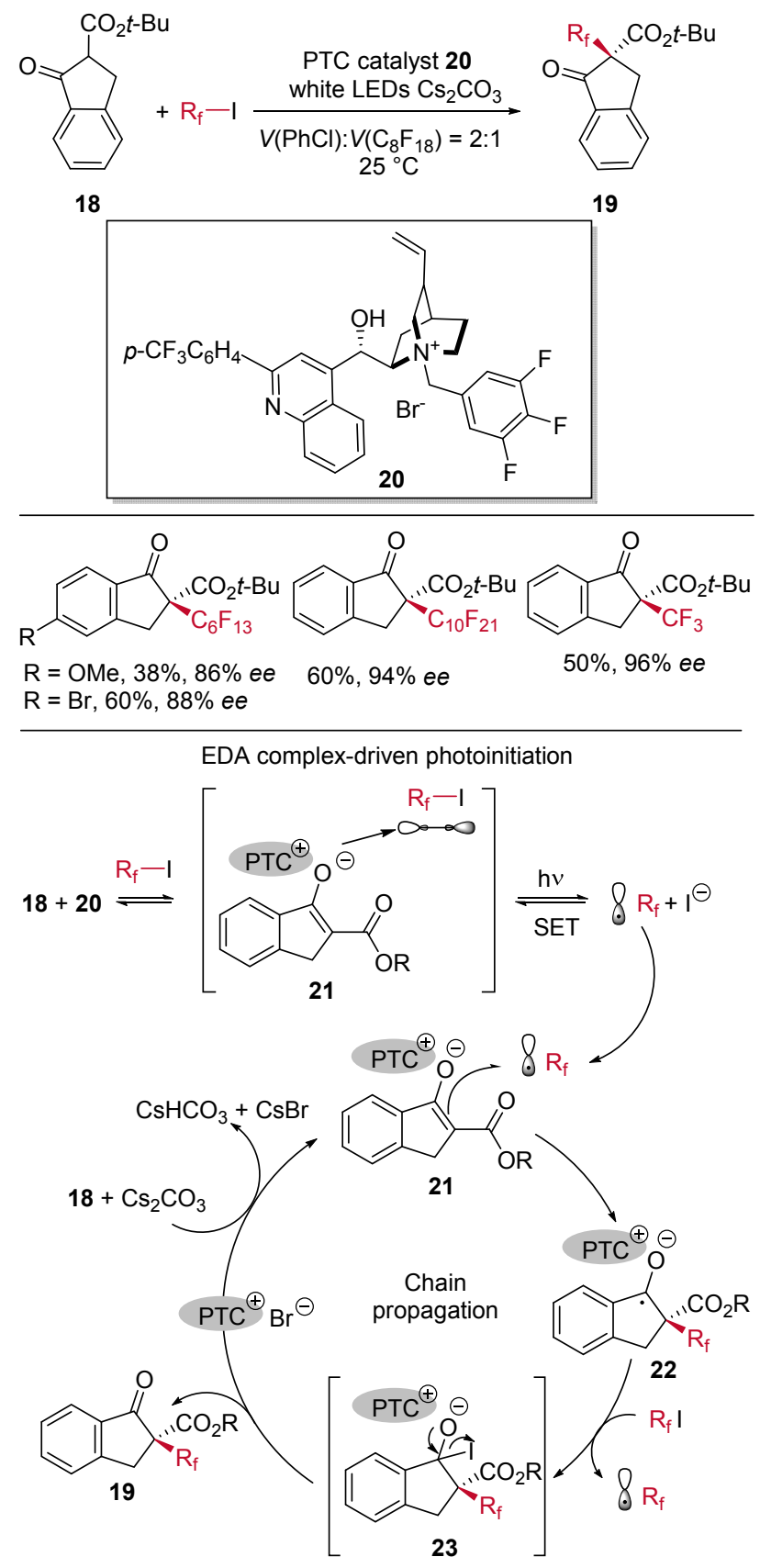

图式 4 可见光驱动相转移催化的 $\beta$-狮酮酸酯的不对称氟烷 基化

Scheme 4 Visible light driven phase transfer catalyzed asymmetric fluoroalkylation of indanone derived $\beta$-ketoesters

\section{3 路易斯酸促进的不对称自由基氟烷基化}

2012 年, Zakarian 等 ${ }^{[15]}$ 实现了钌催化路易斯酸促进 的 $N$-酰基啞唑啉酮 24 的不对称氟烷基化(Scheme 5). 通 过手性辅基的控制，该反应可以兼容各种取代的 $N$-酰 基噁唑啉酮，对羰基 $\beta$ 位的位阻不敏感，适用于含三氟 甲基和全氟烷基的手性中心的高效高选择性构建. 手性 辅基可以通过氧化和还原分别转化为羧基和羟基. 作者
通过核磁可以观察到在碱的作用下 $N$-酰基噁唑啉酮 24 与路易斯酸四氯化锆所形成的手性烯醇式锆盐 26. 由 还原态的二价钉单电子还原相应的氟烷基碘化物产生 的氟烷基自由基对 26 进行立体专一性加成, 得到自由 基中间体，其共振结构为 27 和 $\mathbf{2 8}$, 最后被三价钓氧化 得到最终产物 25, 再生二价钉催化剂完成催化循环.
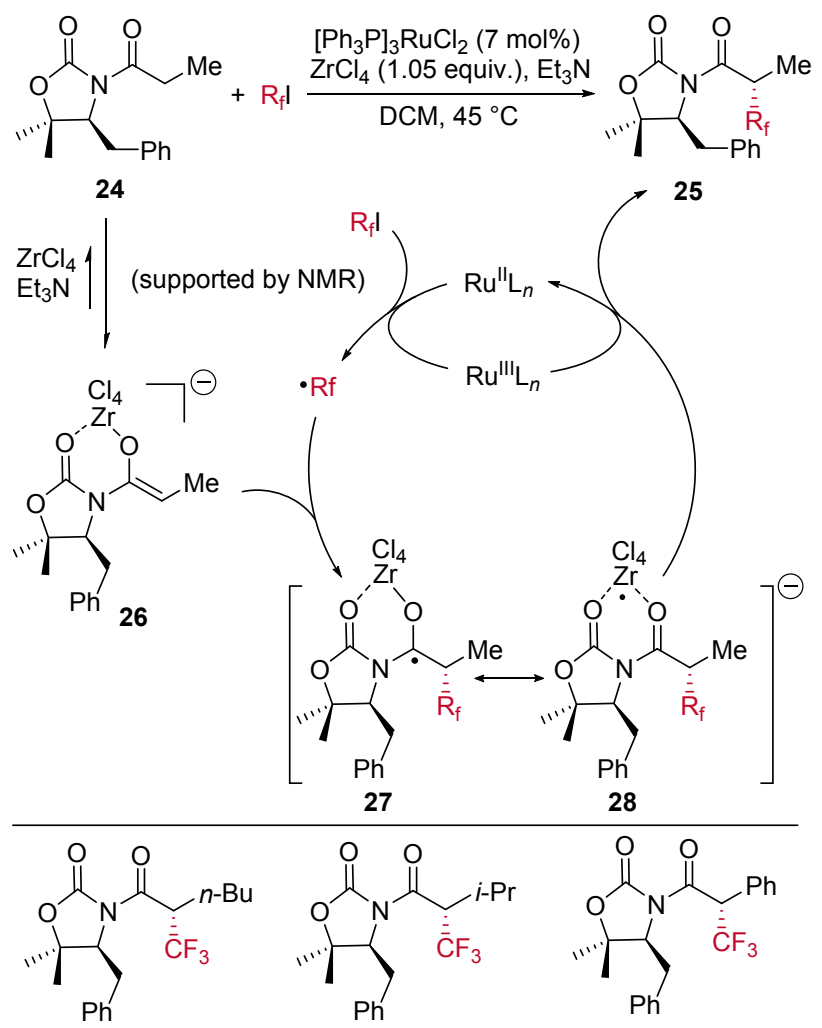

$71 \%, d r=9.4: 1$

$79 \%, d r>98: 2$

$48 \%, d r=9: 1$

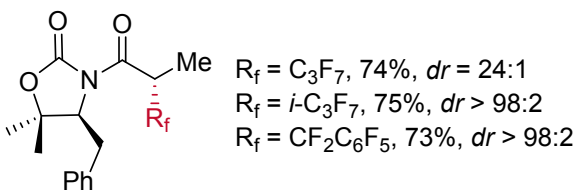

图式 5 钉催化路易斯酸促进的 $N$-酰基噁唑啉酮不对称氟烷 基化

Scheme 5 Ruthenium catalyzed Lewis acid promoted asymmetric fluoroalkylation of $\mathrm{N}$-acyl oxazolinones

2016 年, Meggers 课题组 ${ }^{[16]}$ 实现了铱催化的 2-酰基 咪唑羰基 $\alpha$ 位的不对称氟烷基化(Scheme 6). 该反应中 铱催化剂既是被可见光激发参与氧化还原循环的光敏 剂，又是控制氟烷基化过程对映选择性的手性路易斯酸 催化剂. 反应在室温和弱碱性条件下进行，条件温和, 对映选择性好(93\% 99\% ee)，适用于含三氟甲基和多 种全氟烷基的手性中心的构建. 可能的反应机理为: 首 先手性铱催化剂 31 失去两分子乙腈配体与底物 2-酰基 咪唑 29 的氮氧螯合配位形成中间体 32 , 在弱碱的碳酸 氢钠的存在下算取质子形成铱配位的富电子烯醇中间 体 33, 氟烷基自由基对其进行立体专一性地加成形成 
自由基 34, 随后失去一个电子形成 35, 最后再与底物 29 发生配体交换得到最终产物 $\mathbf{3 0}$, 并再生铱催化剂. 由 34 被氧化释放的电子可以流入光致氧化还原催化循环 或者直接单电子还原全氟烷基碘而引发自由基链反应.

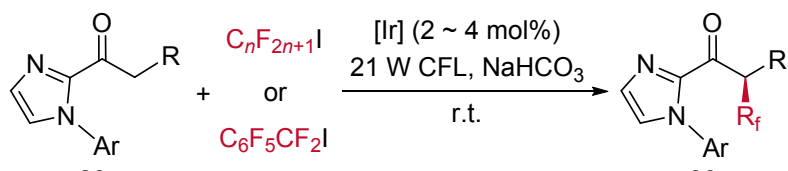

29<smiles>[R]c1ccc(C(C(=O)c2nccn2-c2ccccc2C)C(F)(F)F)cc1</smiles>

$\mathrm{R}^{\prime}=\mathrm{OMe}, 90 \%, 99 \%$ ee $\mathrm{R}^{\prime}=\mathrm{Cl}, 63 \%, 96 \%$ ee

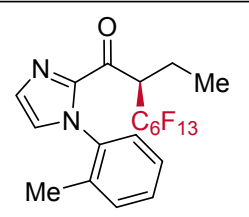

$59 \%, 99 \%$ ee

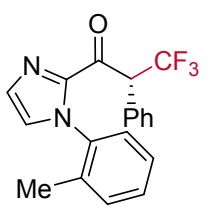

$43 \%, 93 \%$ ee

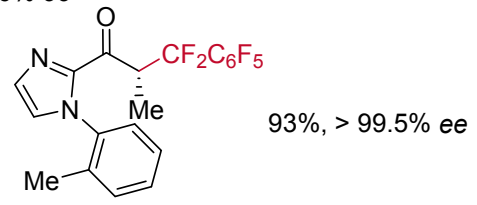

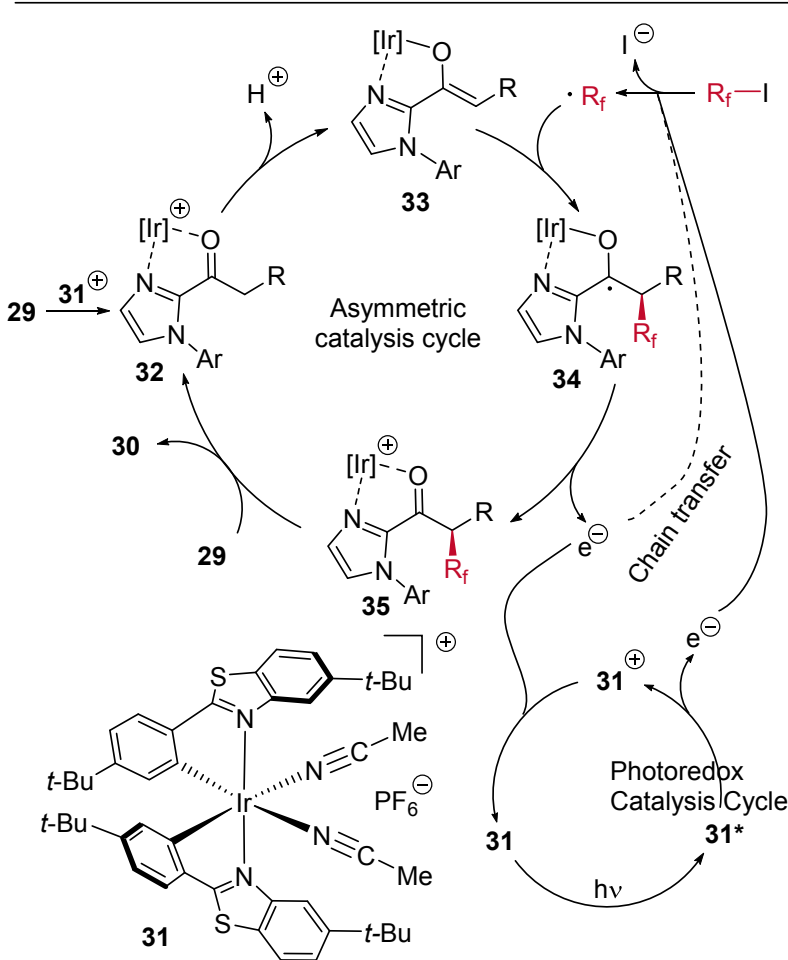

图式 6 可见光促进下手性光敏催化剂催化的 2-酰基咪唑的 不对称氟烷基化

Scheme 6 Visible light induced asymmetric fluoroalkylation of 2-acyl imidazoles catalyzed by a chiral iridium complex

2018 年, 肖文精课题组 ${ }^{[17]}$ 发展了基于光致氧化还 原过程镍催化的 $\beta$-酮酸酯 36 的不对称氟烷基化的新方 法，用于构建含三氟甲基、二氟甲基、全氟烷基的全碳 手性中心(Scheme 7). 该反应在室温下进行, 适用于五 元环和六元环的 $\beta$-酮酸酯底物, 但六元环底物的转化只
能得到较低的对映选择性 $(e r=55: 45)$. 推测的反应机 理包含了光催化循环和路易斯酸催化循环两个部分. 首 先光敏催化剂在光照条件下达到激发态，激发态的三价 铱催化剂具有强氧化性, 将 $\left[\mathrm{Ni} / \mathrm{L}^{*}\right]$ 单电子氧化成 $[\mathrm{Ni} /$ $\left.\mathrm{L}^{*}\right]^{+}$,同时得到光敏催化剂的还原态二价铱物种. 氟烷基 碘代物被二价铱单电子还原产生氟烷基自由基，同时再 生光敏催化剂完成光催化循环. 手性双齿噁唑啉配体配 位的镍催化剂作为手性路易斯酸和 $\beta$-酮酸酯 36 配位形 成烯醇式中间体 38, 氟烷基自由基对该中间体进行对 映选择性地加成生成中间体 39, 最后解离配体得到最 终氟烷基化的产物 37 和 $\left[\mathrm{Ni} / \mathrm{L}^{*}\right]^{-}$物种. $\left[\mathrm{Ni} / \mathrm{L}^{*}\right]^{-}$物种被激 发态的三价铱或 $\left[\mathrm{Ni} / \mathrm{L}^{*}\right]^{+}$所氧化，再生 $\left[\mathrm{Ni} / \mathrm{L}^{*}\right]$ 完成催化 循环。

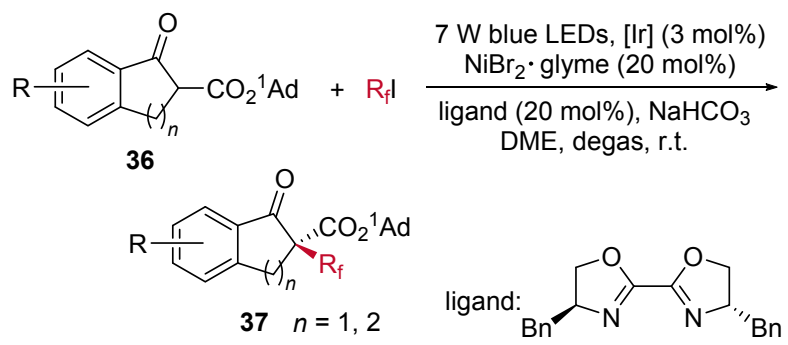

$[\mathrm{Ir}]=\operatorname{Ir}\left[\mathrm{dF}\left(\mathrm{CF}_{3}\right) \mathrm{ppy}\right]_{2}(\mathrm{dtbbpy}) \mathrm{PF}_{6}$, fac-Ir(ppy $)_{3}$
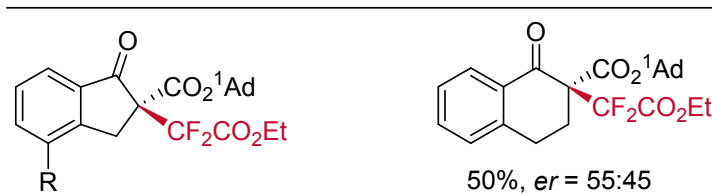

$\mathrm{R}=\mathrm{OMe}, 57 \%$, er $=90.5: 9.5$

$\mathrm{R}=\mathrm{Br}, 47 \%, \mathrm{er}=89: 11$

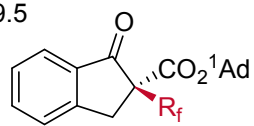

$\mathrm{R}_{\mathrm{f}}=\mathrm{CF}_{2} \mathrm{CO}_{2} \mathrm{Et}, 67 \%$, er $=94: 6$

$\mathrm{R}_{\mathrm{f}}=\mathrm{C}_{4} \mathrm{~F}_{9}, 55 \%$, er $=87: 13$

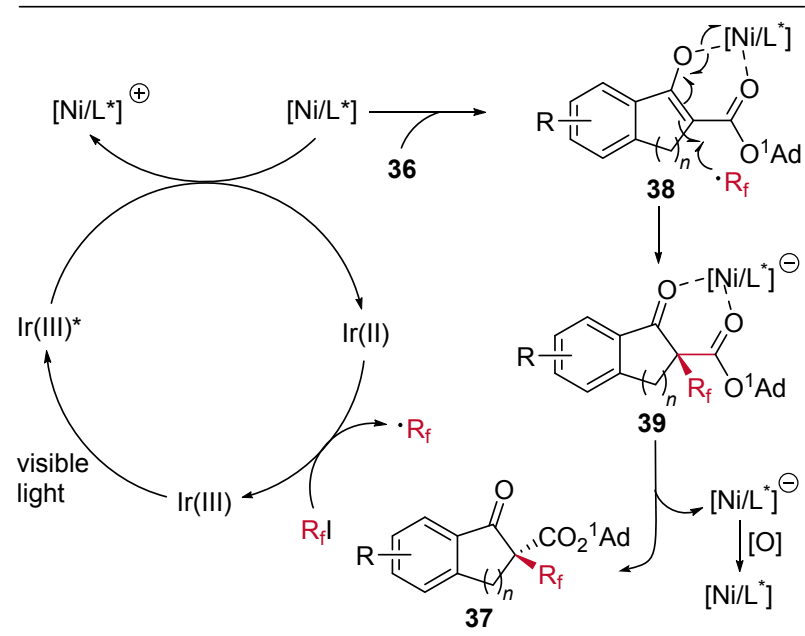

图式 7 可见光促进镍催化的 $\beta$-酮酸酯的不对称氟烷基化

Scheme 7 Asymmetric fluoroalkylation of $\beta$-ketoesters enabled by cooperative photoredox/nickel catalysis 


\section{3 经由氟烷基自由基的烯烃不对称双官能团化}

\section{1 手性辅基控制的烯烃不对称氟烷基双官能团化}

2007 年, Yajima 课题组 ${ }^{[18]}$ 报道了在录灯照射下使用 全氟烷基碘对含有手性辅基的丙烯酸酰胺衍生物 40 进 行碘化全氟烷基化, 生成产物 41, 从而构建羰基 $\alpha$ 位含 碘的手性中心. 但反应的非对映选择性有待提高(Eq. 3).<smiles>CC1(C)C2CC3CC1C(C)(C)C3C2</smiles>

\section{2 铜/含氮手性配体催化的烯烃不对称氟烷基官能团} 化

2013 年, Buchwald 课题组 ${ }^{[19]}$ 首先报道了室温下铜 催化的羧酸取代的烯烃 42 的不对称氧化三氟甲基化反 应，并将该反应用于合成各种三氟甲基取代的手性五元 环和六元环内酯 43 (Scheme 8). 作者对反应机理进行了 初步探索. 无论以 $E$ 型还是 $Z$ 型的三取代烯烃羧酸 45 为反应底物, 得到的产物中四种异构体的比例 46 : $49: 48 ： 47=36: 1: 50 ： 13$, 且三氟甲基相连的手性 中心为 $S$ 构型的产物(46 和 47)与 $R$ 构型(48 和 49)的产 物的量基本相同. 据此作者认为烯烃 Wacker 类型的氧 化铜化途径可以完全被排除 ${ }^{[20]}$, 而烯烃的双官能化是 分步进行的，其中三氟甲基自由基对烯烃的加成形成碳 碳键的过程是没有立体选择性的. 因此三氟甲基自由基 无论对底物 $(E)-45$ 还是 $(Z)-45$ 加成, 均得到等比例的中 间体 $(S)-50$ 与 $(R)-50$. 在接下来的碳氧键的形成过程中, 手性配体 44 配位的 $\left[\mathrm{Cu}(\mathrm{MeCN})_{4}\right] \mathrm{PF}_{6}$ 和已形成的三氟甲 基取代的手性中心，都会对成键的立体构型产生影响， 造成了匹配与不匹配的情况. 对于中间体 $(S)-50$, 由催 化剂控制的选择性 $(6 R$ 优于 $6 S)$ 与底物结构控制的选择 性(6S, 2'S 优于 $\left.6 R, 2^{\prime} S\right)$ 相反, 因此选择性降低至 $36: 13$. 而对于中间体 $(R)-50$, 由于催化剂控制的选择性 $(6 R$ 优 于 $6 S)$ 与底物结构控制的选择性 $\left(6 R, 2^{\prime} R\right.$ 优于 $\left.6 S, 2^{\prime} R\right)$ 一 致，使得选择性增强至 50：1 (Scheme 8).

推测的反应机理为: 首先反应使用的 Togni 试剂 II, 在一价铜和手性配体 44 催化体系作用下, 被单电子还 原产生亲电的三氟甲基自由基, 对羧基取代的烯烃底物 进行自由基加成, 形成烷基自由基中间体 50, 然后在二 价铜和手性配体 44 的作用下, 对映选择性地形成碳氧 键, 得到手性内酯产物 51, 并再生催化剂完成催化循环 (Scheme 8).
44
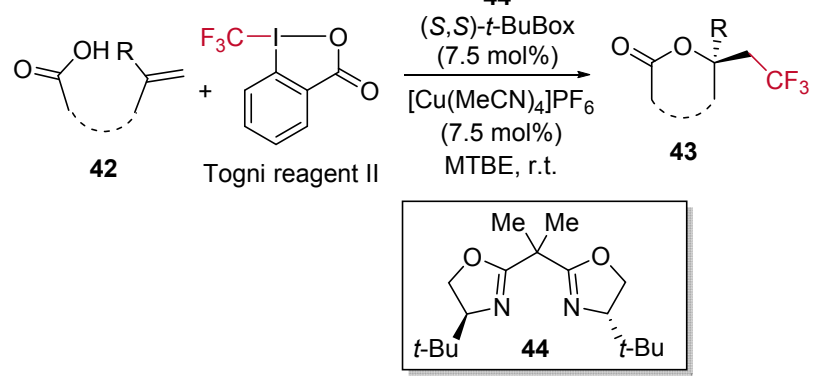

$\underbrace{\mathrm{Ph}}_{\mathrm{CF}_{3}}$ $88 \%, 82 \%$ ee $\quad 72 \%, 80 \%$ ee $\quad 85 \%, 83 \%$ ee $\quad 85 \%, 81 \%$ ee $\underbrace{\mathrm{Me}}_{(E)-\mathbf{4 5}, E: Z>20: 1}$<smiles>C[C@H](C(F)(F)F)C1([18O])CCCC(=O)O1</smiles>

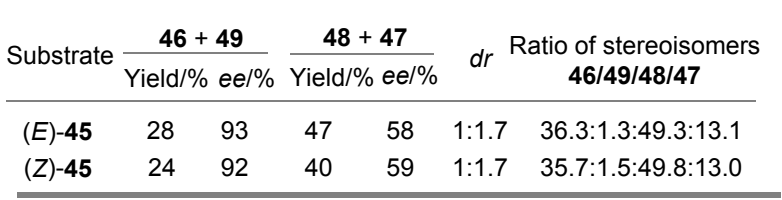
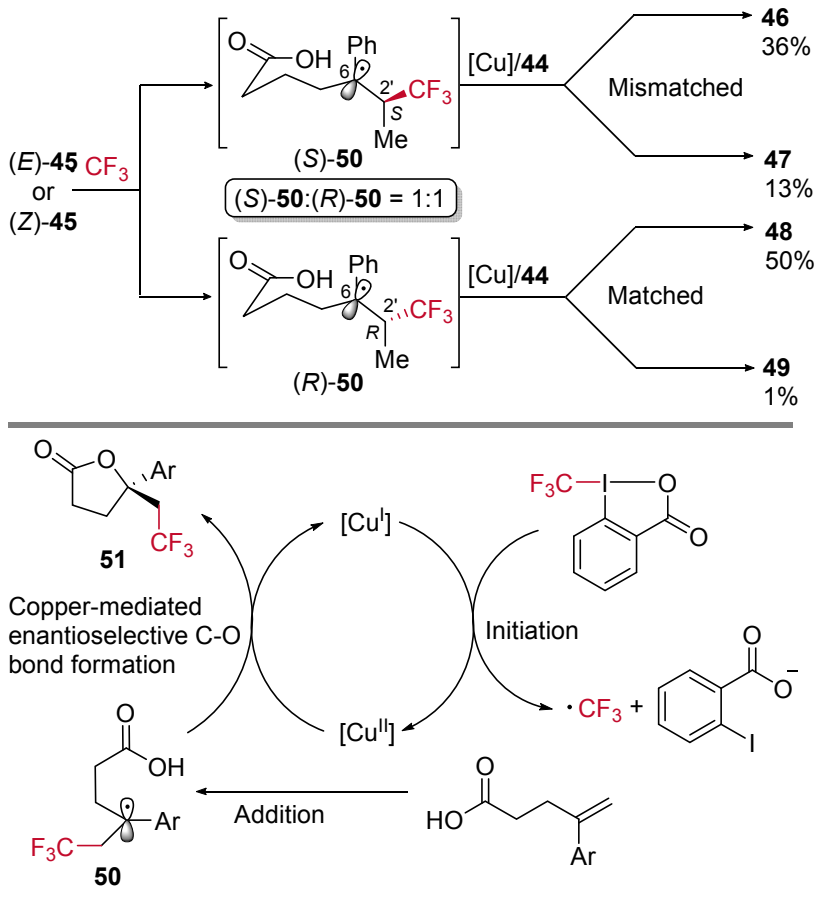

图式 8 铜催化的烯烃不对称酯化三氟甲基化反应 Scheme 8 Cu-catalyzed asymmetric trifluoromethylesterification of alkenes

2016 年, 刘国生课题组 ${ }^{[21]}$ 报道了使用 Togni 试剂 I 
为三氟甲基来源，三甲基氰硅烷(TMSCN)为氰基化试 剂, 在一价铜和手性配体 $\mathbf{5 3}$ 催化下, 对一系列苯乙烯衍 生物进行不对称氧基三氟甲基双官能化得到产物 52 (Scheme 9). 该反应官能团耐受性好, 杂环烯烃也是合 适的反应底物, 对于一般烷基取代的末端烯烃底物转化 的对映选择性低.

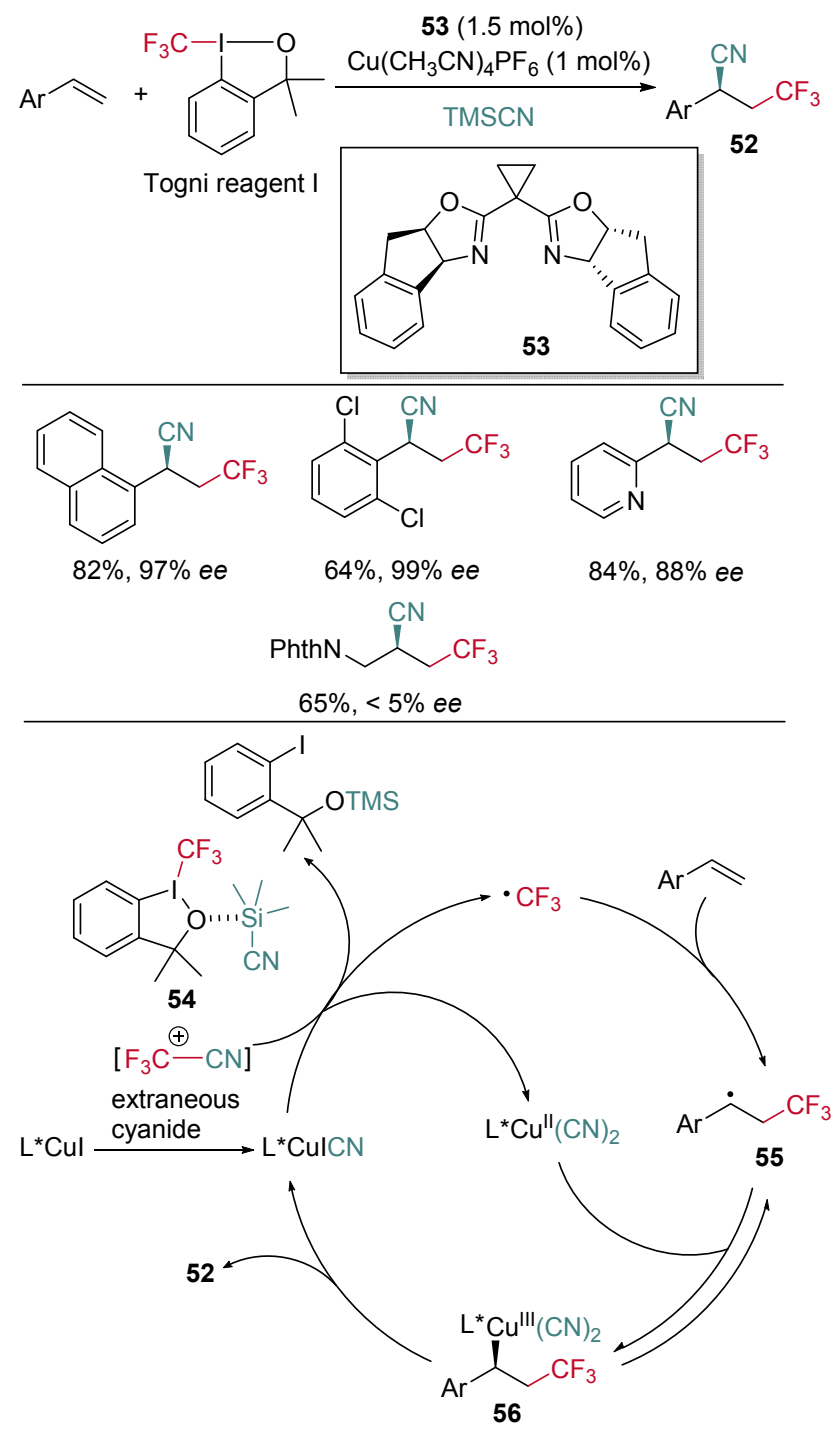

图式 9 铜催化的烯烃不对称氰基三氟甲基化

Scheme $9 \mathrm{Cu}$-catalyzed asymmetric cyanotrifluoromethylation of alkenes

作者发现该反应存在诱导期，在诱导期内只能观察 到少量苄基自由基自偶联的产物，而没有目标产物形 成. 当反应体系中加入四丁基氰化胺时, 随着其浓度的 不断增大 $(0.4 \sim 2 \mathrm{~mol} \%)$, 反应的诱导期随之缩短并且最 后消失，对于对映选择性没有明显影响. 但当四丁基氰 化铵的浓度增至 $20 \mathrm{~mol} \%$ 时(相当于铜催化剂的浓度的 十倍), 反应速度变得更慢, 且产物 $e e$ 值下降到 $15 \%$. 因 此, 作者推断增加氰负离子的浓度将影响手性配体与铜
的配位. 因此作者认为反应过程中 Togni 试剂 I 和 TMSCN 之间形成了复合物 54, 这种相互活化模式使得 氰离子缓慢释放. 该复合物与原位产生的 $\mathrm{LCu}{ }^{\mathrm{I}} \mathrm{CN}$ 发生 单电子转移, 形成 $\mathrm{LCu}^{\mathrm{II}}(\mathrm{CN})_{2}$ 与三氟甲基自由基, 对苯 乙烯底物进行自由基加成得到 55 , 再与 $\mathrm{LCu}^{\mathrm{II}}(\mathrm{CN})_{2}$ 结合 得到三价铜中间体 $\mathbf{5 6}$, 最后还原消除得到最终产物 52 .

随后，刘国生课题组 ${ }^{[22]}$ 使用芳基硼酸实现了烯烃 的立体专一性的芳基三氟甲基化(Scheme 10). 该反应
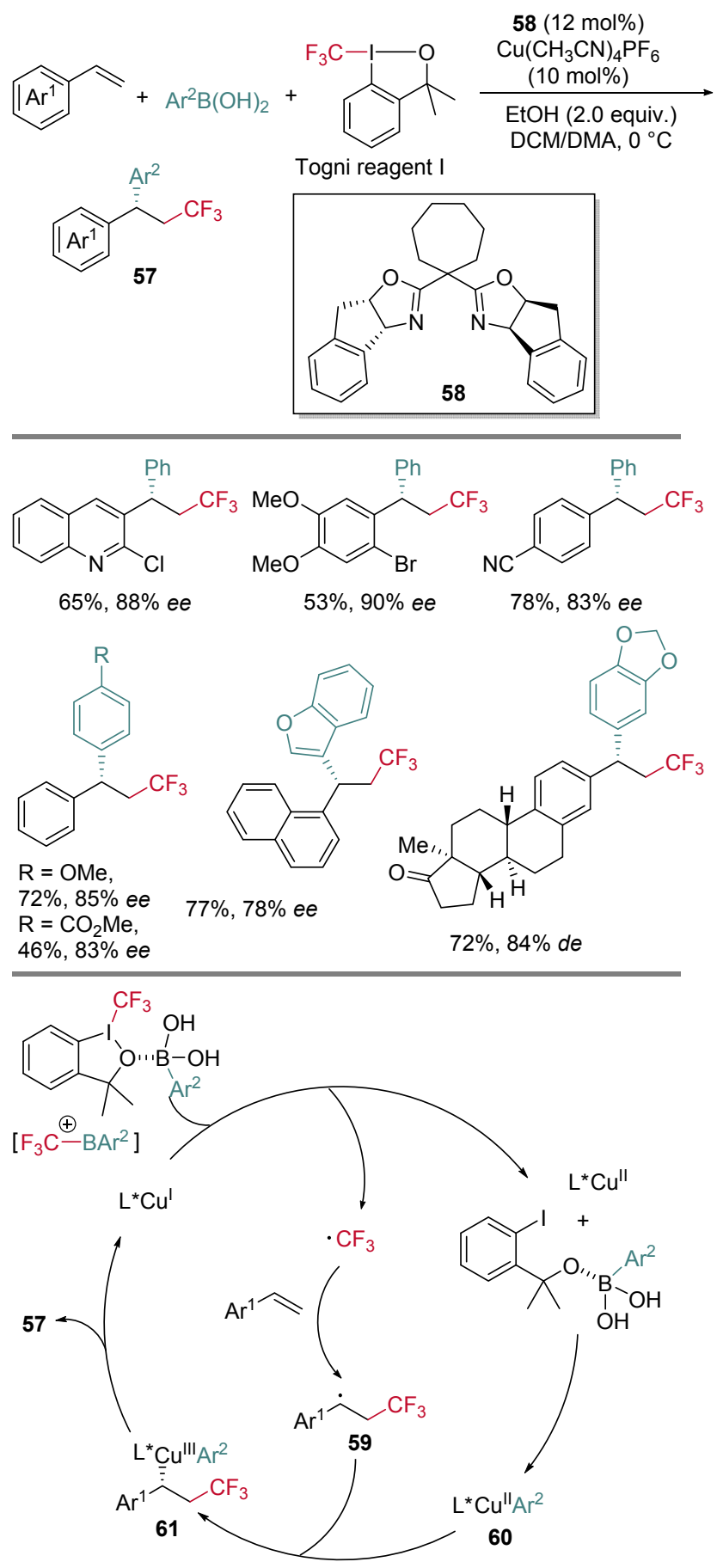

图式 10 铜催化的烯烃不对称芳基三氟甲基化

Scheme $10 \mathrm{Cu}$-catalyzed asymmetric aryltrifluoromethylation of alkenes 
条件温和、反应兼容各种电性的苯乙烯和芳杂环乙烯衍 生物. 反应机理与之前所描述的氰基三氟甲基化类似, 芳基硼酸同样可以活化 Togni 试剂 I 使其在一价铜的单 电子还原下产生三氟甲基自由基, 再对烯烃进行加成得 到 59, 同时这种相互活化也促进了芳基硼酸的转金属 过程, 形成芳基二价铜 60 , 随后自由基 59 与二价铜 60 加成产生三价铜中间体 61, 芳基在三价铜中心还原消 除得到最终产物 57.

2018 年, 刘国生课题组 ${ }^{[23]}$ 继续通过铜催化的自由 基接力(radical relay), 实现了苯乙烯类底物对映选择性 的炔基三氟甲基化(Eq. 4). 反应使用 Togni 试剂 I 为三氟 甲基来源, 手性双齿啞唑啉 62 为配体, 底物范围广, 官 能团耐受性好, 杂环烯烃也可在该条件下高效转化. 反 应所得到的手性产物经过炔基的进一步转化, 可以合成 包括布洛芬(Ibuprofen)与氟比洛芬(Flurbiprofen)衍生物 在内的多种中间体，体现了该方法在合成中的应用价 值.

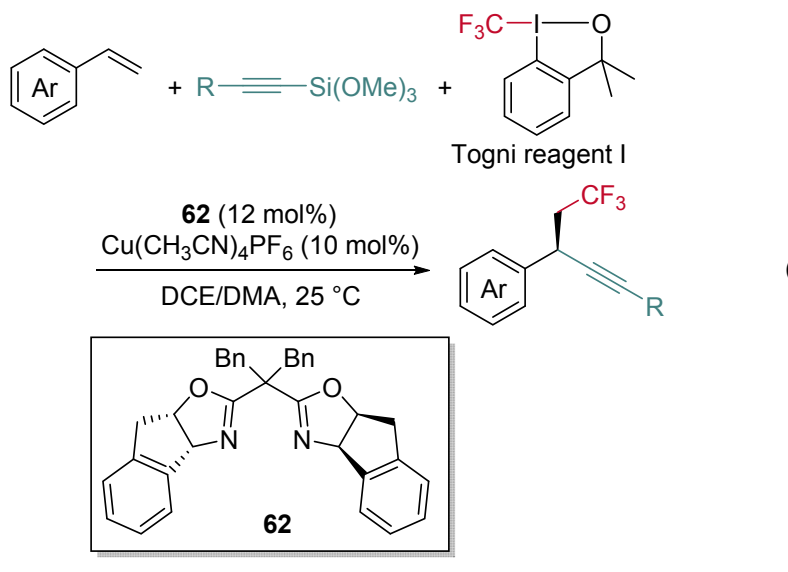

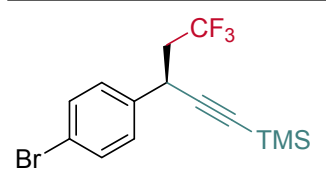

$80 \%, 92 \%$ ee $82 \%, 92 \%$ ee (gram scale)<smiles>CC#CC(CC(F)(F)F)c1ccc(Oc2ccccc2)c(F)c1</smiles>

$70 \%, 90 \%$ ee<smiles>COCC#C[C@H](CC(F)(F)F)c1ccccc1</smiles>

$65 \%, 92 \%$ ee<smiles>COC(C)(F)C(F)(F)F</smiles>

$70 \%, 95 \%$ ee<smiles>CC#CC(CC(F)(F)F)c1cnn(-c2ccccc2)c1</smiles>

$\mathrm{Ph} 72 \%, 88 \%$ ee<smiles>FC(F)(F)C[C@H](C#Cc1ccccc1)c1ccccc1</smiles>

$73 \%, 91 \%$ ee

\section{3 铜/手性磷酸催化的烯烃不对称氟烷基官能团化}

2014 年, 刘心元课题组 ${ }^{[24]}$ 利用一价铜和手性磷酸 (CPA)协同催化体系, 实现了未活化烯烃自由基三氟甲 基化引起的酰胺 $\alpha$ 位碳氢键不对称烷氧基化(Scheme
11). 反应机理为: 在一价铜催化剂和手性磷酸 64 的协 同作用下单电子还原 Togni 试剂 I，产生亲电的三氟甲基 自由基, 再对底物 63 的双键进行加成形成二级烷基自 由基中间体 66, 再发生分子内的 1,5-氢原子转移(HAT), 形成更稳定的酰胺 $\alpha$ 位苄基自由基中间体 67. 二价铜对 其进行第二次单电子氧化得到亚胺 68 , 在手性磷酸与 亚胺以及醇之间的氢键作用下, 接受醇的亲核进攻, 经
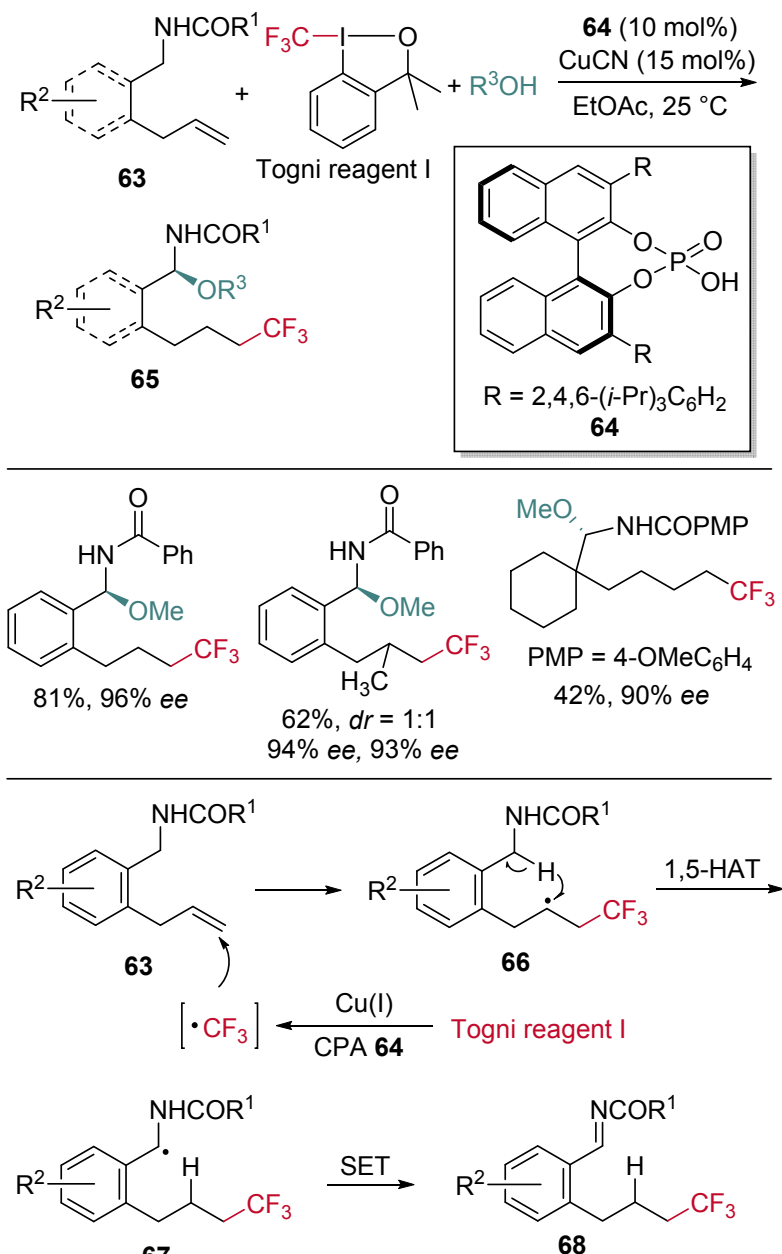

67

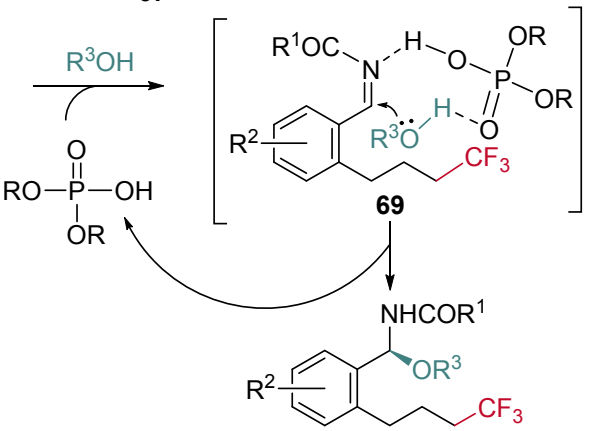

65

图式 11 铜催化的烯烃自由基三氟甲基化引起的碳氢键不对 称烷氧基化

Scheme $11 \mathrm{Cu}$-catalyzed asymmetric C-H alkoxylation triggered by radical trifluoromethylation of alkenes 
由 69 形成最终的多官能团化的产物 65 . 在底物普适性 研究中, 作者发现 1,1-二取代烯烃底物也可以得到兼容, 通过该反应得到一对等量的高对映选择性的非对映异 构体. 反应对于酰胺 $\alpha$ 位为亚甲基的底物也同样适用, 转化可以获得较高的对映选择性.

2017 年, 刘心元课题组 ${ }^{[25]}$ 将一价铜和手性磷酸的 协同催化体系拓展应用到吲哚作为亲核试剂的三组分 反应中, 构建手性的碳碳键. 反应机理与 Scheme 11 所 描述的类似, 不同之处在于在手性磷酸 $(\mathrm{CPA})$ 的活化下, 发生了富电子吲哚 70 对亚胺的不对称傅-克反应. 该室 温下吲哚的不对称碳氢键官能团化反应底物普适, 适用 于合成一系列含有三氟甲基取代基的手性吲哚衍生物 71 (Eq. 5).

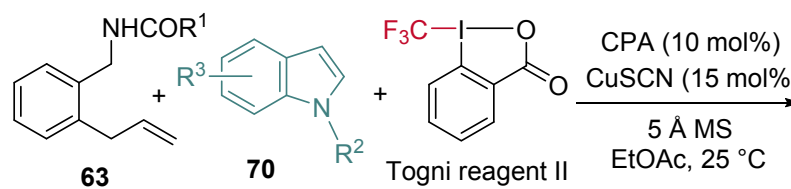

63

$70 \mathrm{R}^{2}$ Togni reagent II

EtOAc, $25^{\circ} \mathrm{C}$

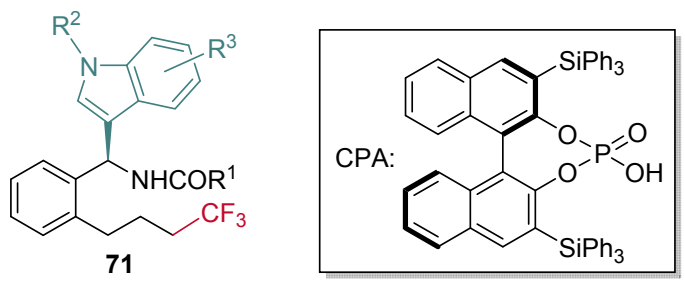

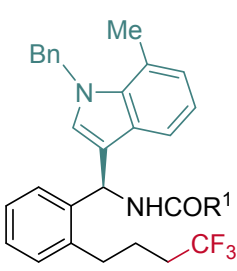

$\mathrm{R}^{1}=4-\mathrm{MeC}_{6} \mathrm{H}_{4}$ $63 \%, 63 \%$ ee $\mathrm{R}^{1}=4-\mathrm{ClC}_{6} \mathrm{H}_{4}$, $66 \%, 76 \%$ ee

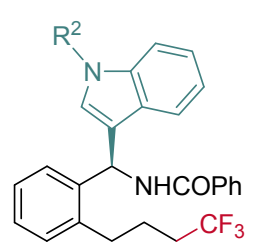

$\mathrm{Bn}$<smiles>[R]c1ccc2c(c1)c(C(NC(=O)c1ccccc1)c1ccccc1CCCC(F)(F)F)cn2Cc1ccccc1</smiles>

$\mathrm{R}^{2}=4-\mathrm{MeOC}_{6} \mathrm{H}_{4}$ $54 \%, 85 \%$ ee

$\mathrm{R}^{3}=\mathrm{H}, 59 \%, 88 \%$ ee $\mathrm{R}^{2}=4-\mathrm{BrC}_{6} \mathrm{H}_{4}$ $45 \%, 80 \%$ ee
2016 年, 刘心元课题组 ${ }^{[26]}$ 基于一价铜和手性磷酸 74 协同催化实现了含脲的烯烃 72 的不对称胺化三氟甲 基化过程，合成了一系列手性吡咯烷(Scheme 12). 反应 机理为: 单电子还原过程所产生的三氟甲基自由基对双 键加成生成中间体 75, 再经三价铜中间体 76 生成最终 产物 73. 而中间体 75 被单电子氧化, 得到碳正离子中 间体，再接受亲核进攻，构建手性碳氮键的反应途径并 不能被排除。值得注意的是，反应使用了嫝作为氮源， 脲上的其中一个氮氢被算取质子与铜的阴离子发生配 体交换, 另一个氮氢则与手性磷酸形成氢键配位, 控制 反应的对映选择性. 这与当使用甲基保护的䐖衍生物 77 为底物时反应不能发生这一实验结果相吻合. 该反 应在室温下进行, 兼容给电子和吸电子基取代的苯乙
烯，并且适用于偕二烷基或酯基取代具有 Thorpe-Ingold 效应的底物.

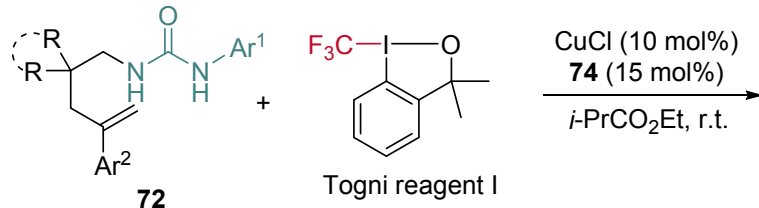

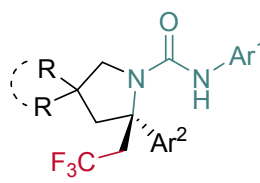

73

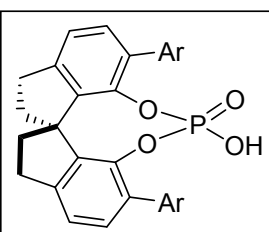

$74 \mathrm{Ar}=4-\mathrm{PhC}_{6} \mathrm{H}_{4}$

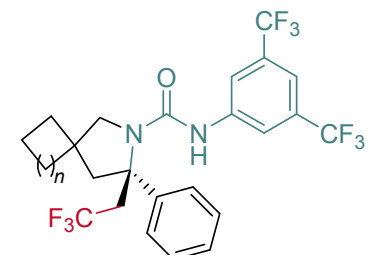

$n=1,78 \%, 88 \%$ ee $n=4,71 \%, 88 \%$ ee

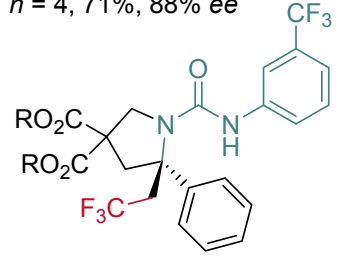

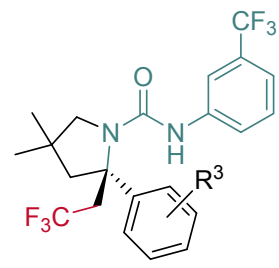

$\mathrm{R}^{3}=3-\mathrm{OMe}, 76 \%$, $94 \%$ ee $\mathrm{R}^{3}=3-\mathrm{F}, 55 \%, 96 \%$ ee

$\mathrm{R}=\mathrm{Et}, 60 \%, 95 \%$ ee $\mathrm{R}=t-\mathrm{Bu}, 54 \%$, 88\% ee

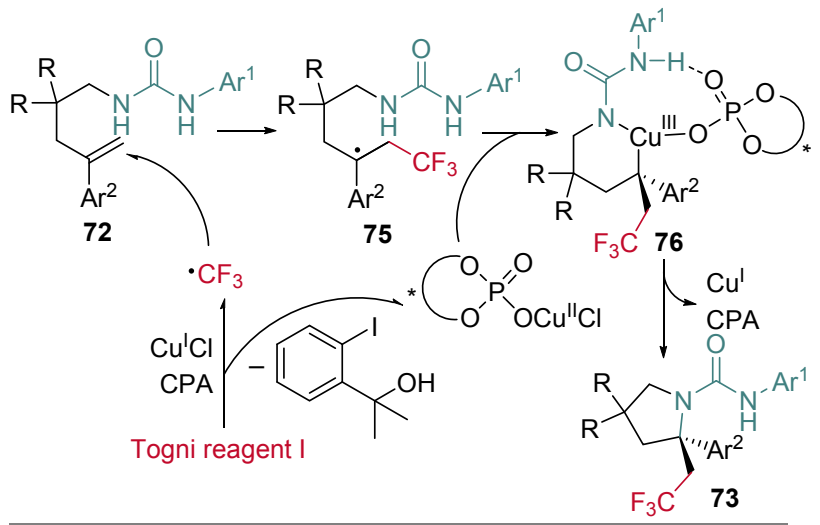

Mechanistic study<smiles></smiles><smiles>COc1cccc(N(C)C(=O)N2CC(C)(C)C[C@]2(CC(F)(F)F)c2ccccc2)c1</smiles>

图式 12 铜催化的烯烃不对称胺化三氟甲基化

Scheme 12 Cu-catalyzed asymmetric aminotrifluoromethylation of alkenes 
同年, 刘心元等 ${ }^{[27]}$ 使用相同的底物与策略, 改用更 廉价的氟烷基磺酰氯代替 Togni 试剂 I 作为氟烷基源, 将该类转化的底物范围拓宽到二氟甲基和全氟烷基, 对 甲苯磺酰胺底物也可在该条件下兼容，但反应的对映选 择性明显下降 $(73 \%, 50 \% e e)$. 此外, 不具有 ThorpeIngold 效应的底物也可在该条件下得到兼容, 顺利转化 得到相应的手性四氢吡咯 $78(60 \%, 91 \% e e)$. 而使用 Togni 试剂 I 为三氟甲基源, 反应产率和对映选择性均较 低 $(25 \%, 51 \% e e)$. 转化中碳酸银的作用是为了除去反应 中产生的氯化氢以抑制氢胺化副反应(Eq. 6).

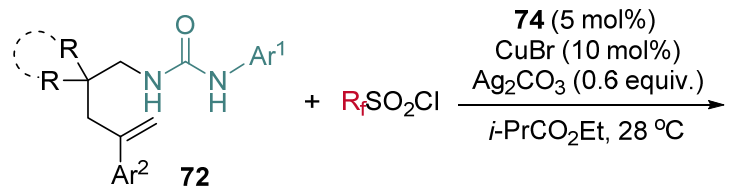

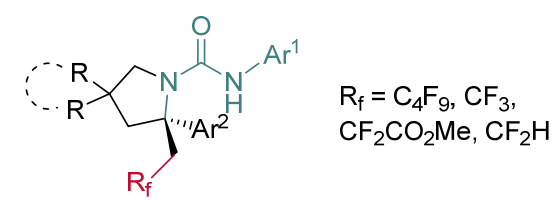

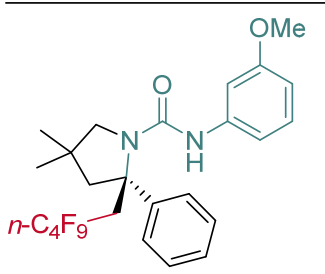

$95 \%, 92 \%$ ee

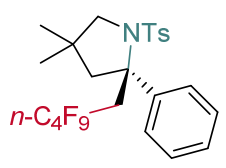

$73 \%, 50 \%$ ee<smiles>CC1(C)CN(C(=O)Nc2cc(C(F)(F)F)cc(C(F)(F)F)c2)[C@](CC(F)F)(c2ccccc2)C1</smiles>

$76 \%, 85 \%$ ee

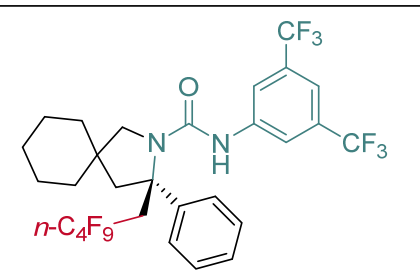

$98 \%, 99 \%$ ee

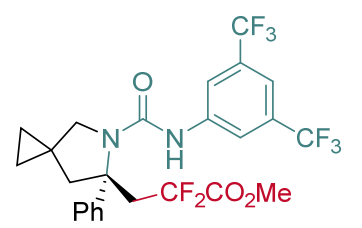

$95 \%, 95 \%$

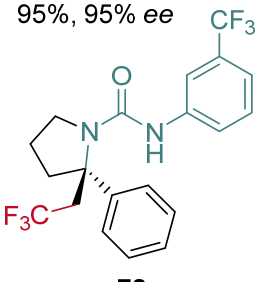

78

$60 \%, 91 \%$ ee

Togni reagent, $25 \%, 51 \%$ ee
2017 年, 刘心元课题组 ${ }^{[28]}$ 使用烯基醇类化合物 79, 在一价铜和手性磷酸(CPA) 81 协同催化下, 使用非手性 的吡啶酰胺 82 作为配体, 实现了烯烃的不对称自由基 氧化三氟甲基化, 以高对应选择性构建了一系列含 $\alpha$ 位 季碳手性中心的三氟甲基化的四氢呋喃衍生物 80 (Scheme 13). 相比之前工作中所使用的嫝类衍生物底 物 ${ }^{[26,27]}$, 由于烯基醇类底物中的羟基氢与手性磷酸 (CPA)作用形成了较弱的氢键以及羟基氧与铜催化剂作 用形成较弱的配位作用, 导致反应的立体选择性较差.
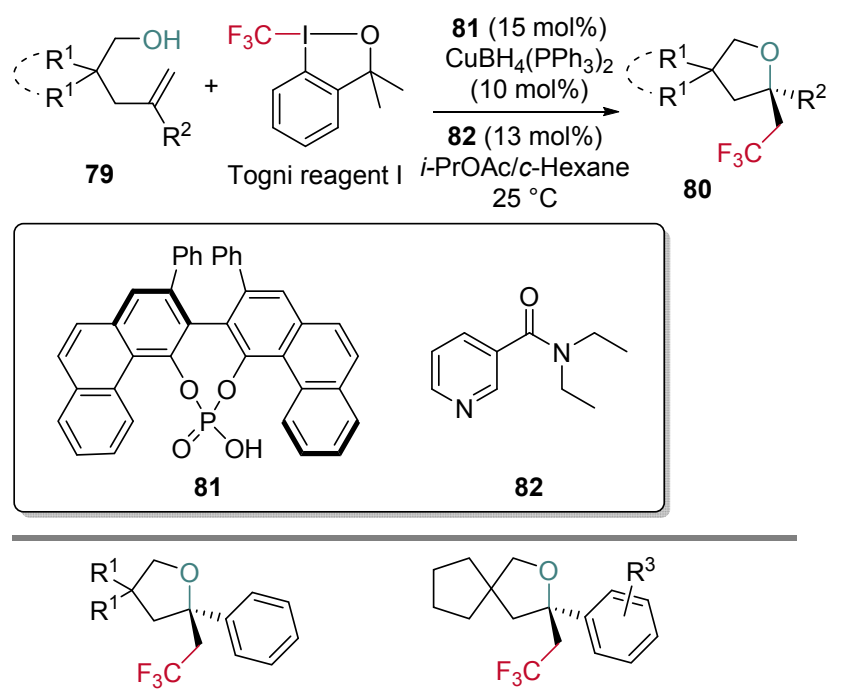

$\mathrm{R}^{1}, \mathrm{R}^{1}=\left(\mathrm{CH}_{2}\right)_{4}, 78 \%, 93 \%$ ee $\quad \mathrm{R}^{3}=2-\mathrm{Me}, 66 \%, 86 \%$ ee $\mathrm{R}^{1}=\mathrm{CH}_{3}, 77 \%, 91 \%$ ee $\quad \mathrm{R}^{3}=3-\mathrm{CF}_{3}, 61 \%, 90 \%$ ee
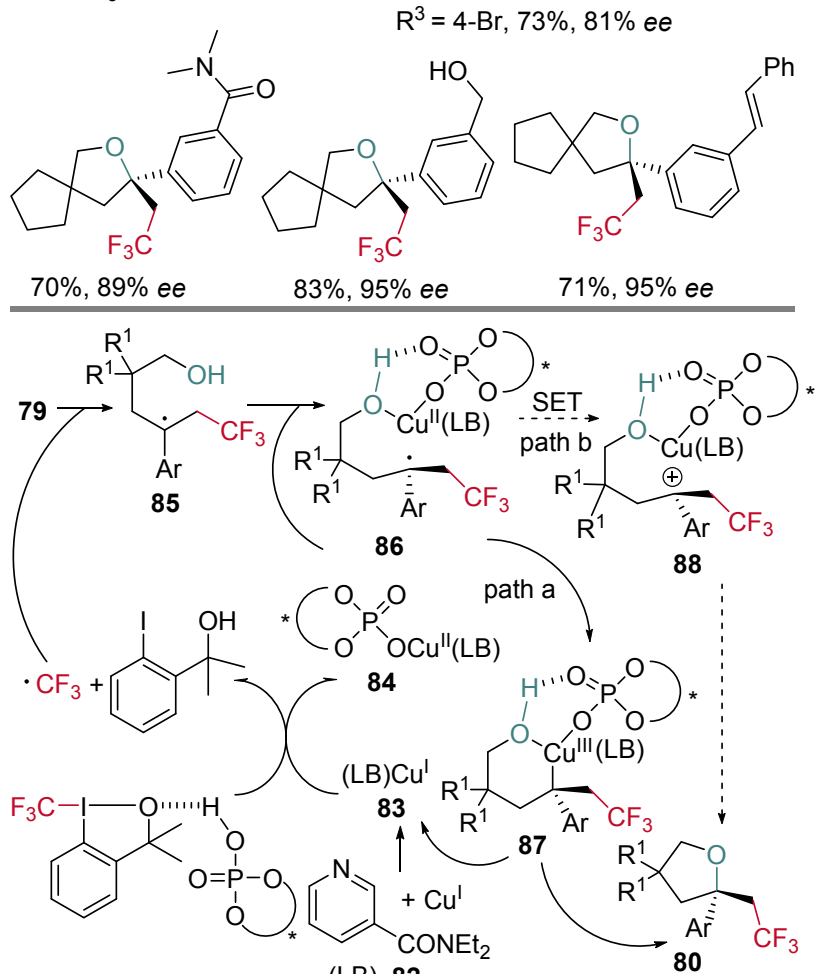

(LB), 82

图式 13 铜催化的烯烃不对称烷氧化/三氟甲基化

Scheme $13 \mathrm{Cu}$-catalyzed asymmetric oxytrifluoromethylation of alkenes

为解决这一问题，作者通过使用吡啶衍生物 82 作为路 易斯碱与铜中心配位，有助于稳定三价铜中间体，使反 应的对映选择性提高至 $93 \%$. 作者推测可能的反应机理 为: 首先非手性的吡啶衍生物 82 与一价铜配位, 得到中 间体 83. 中间体 83 与被手性磷酸 (CPA) 活化的 Togni 试 剂 I 之间发生单电子转移, 得到手性二价铜物种 84 与三 氟甲基自由基. 三氟甲基自由基对烯烃加成所得到的烷 基自由基中间体 85 再对二价铜物种 84 配位得到中间体 
86, 进一步加成得到三价铜中间体 87 (path a), 手性磷 酸 $(\mathrm{CPA})$ 与非手性吡啶配体协同作用稳定了铜中间体 86 和 87 , 实现了立体选择性的控制. 最后, 中间体 87 经 过还原消除得到最终产物 80 . 而二价铜自由基中间体 86 分子内单电子氧化, 经由碳正离子中间体 88 的反应 途径(path b) 并不能被排除.

2018 年, 刘心元课题组 ${ }^{[29]}$ 报道了一例铜催化的含 肜的烯烃 89 的氮氧化三氟甲基化反应(Scheme 14). 该 反应在低温下进行, 使用金鸡纳碱衍生的磺酰胺 91 作 为铜催化剂的手性配体, Togni 试剂 I 作为三氟甲基源, 肜作为分子内的亲核试剂, 以高产率和高对映选择性得 到烯烃不对称氮氧化三氟甲基化的产物 90 . 该转化对 各种给电子和吸电子取代基, 以及各种杂环都有很好的 兼容性. 反应同样经历了单电子还原所产生的三氟甲基 自由基对烯烃自由基加成过程, 依次形成自由基中间体 92, 93 和立体专一的三价铜中间体 94 , 最后经由还原消 除得到最终产物 90. 当铜催化剂和配体 91 混合时, 磺 酰胺中氮氢键的红外信号 $\left(v=3237 \mathrm{~cm}^{-1}\right)$ 会逐渐消失. 此外, 单电子还原 Togni 试剂的活性手性一价铜中间体 95 可以被高分辨质谱所检测到. 当使用甲基取代的配 体 96 时, 反应产率依然很高但对映选择性却很低 $(91 \%$, 3\% ee). 这些结果明确了手性配体与中心金属铜的配位 形式和配体的作用, 即磺胺基团失去质子得到的氮负离 子作为单齿配体与一价铜作用, 但三级胺氮原子作为碱 活化肜羟基的过程仍不能被排除.

\section{4 经由氟烷基自由基的烯基硼酸酯酸根型复合 物立体选择性 1,2-迁移}

2017 年, Studer 课题组 ${ }^{[30]}$ 报道了一例碘代全氟正丁 烷与手性芳基-烯基 $(+)$-蒎烷二醇硼酸酯酸根型复合物 98 反应，合成了全氟烷基取代的手性二级醇 99 (Scheme 15). 反应中的手性硼酸酯 97 商业可得, 与苯基锂试剂 在低温下反应得到相应的手性芳基-烯基硼酸酯酸根型 复合物 98, 再与碘代全氟正丁烷依次发生单电子还原 产生全氟丁基自由基、自由基加成、单电子氧化、苯基 1,2-迁移系列过程, 得到手性二级硼酸酯中间体, 最后 在双氧水作用下氧化脱硼, 以 $52 \%$ 的 $e e$ 值得到全氟烷 基取代的手性二级醇 99.

2018 年, Studer 课题组 ${ }^{[31]}$ 实现了通过碘代全氟烷烃 与二级烷基-烯基频那醇硼酸酯酸根型复合物 101 的反 应, 构建酮羰基 $\alpha$ 位的手性中心. 手性二级烷基频那醇 硼酸酯 100 与乙烯基锂在 $-78{ }^{\circ} \mathrm{C}$ 反应得到手性二级烷 基一烯基频那醇嗍酸酯酸根型复合物 101, 在光照条件 下，与碘代全氟烷烃反应，得到全氟烷基取代的手性嗍 酸酯 102, 再在双氧水作用下氧化脱硼, 得到全氟烷基
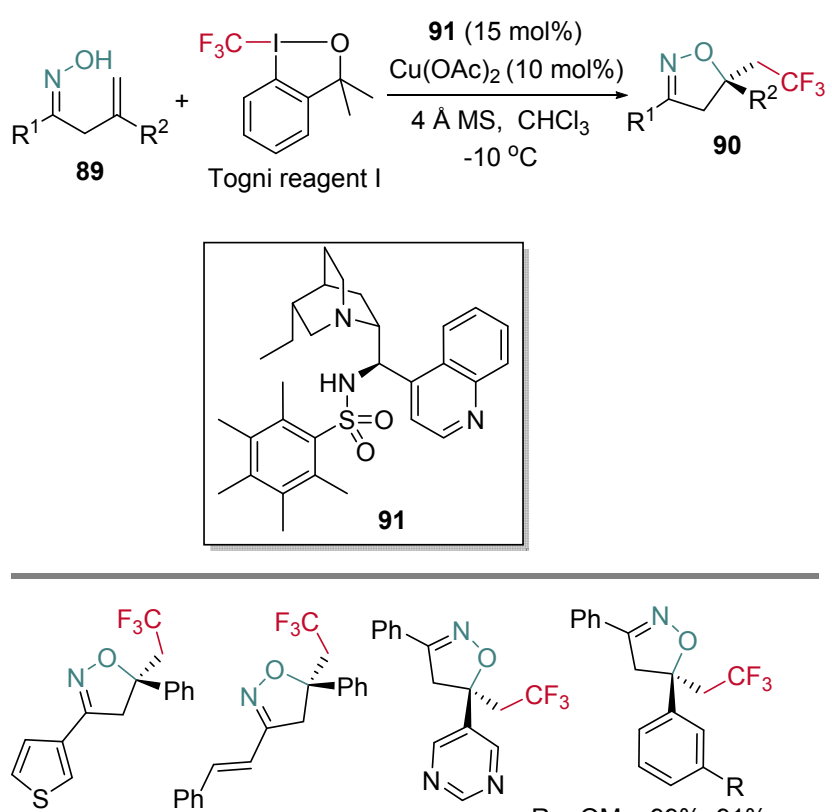

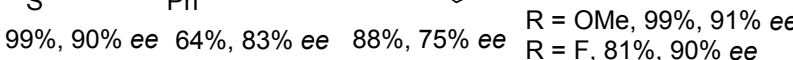
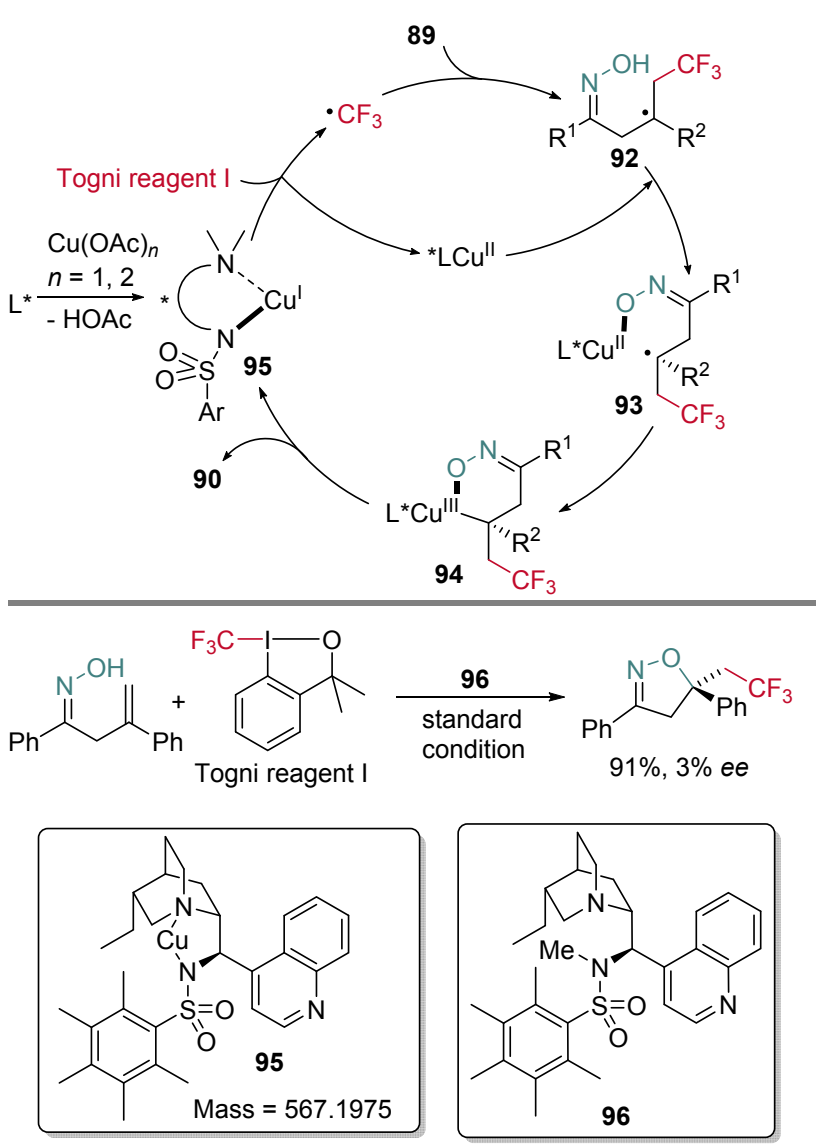

图式 14 铜催化的烯烃不对称氮氧化三氟甲基化

Scheme 14 Cu-catalyzed asymmetric oxytrifluoromethylation of alkenyl oximes

取代的手性酮 103. 值得注意的是, 103 在硅胶柱层析分 离过程中并不稳定, 最终消除一分子氟化氢得到立体专 一的全氟烷基取代 $\alpha, \beta$ 不饱和酮 104 (Scheme 16). 


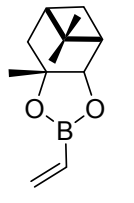

97

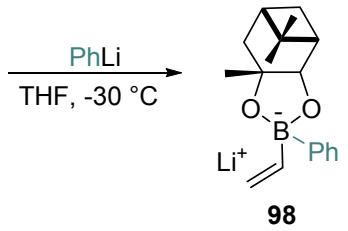

$\underset{\mathrm{CHF},-30{ }^{\circ} \mathrm{C}}{\mathrm{C}_{9} \mathrm{Il}, \mathrm{Et}_{3} \mathrm{~B}}$
then $\mathrm{NaOH}, \mathrm{H}_{2} \mathrm{O}_{2}$

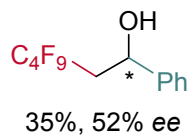

99

图式 15 全氟烷基碘代烷诱导的芳基-烯基(+)-蒎烷二醇硼 酸酯酸根型复合物的芳基 1,2-迁移

Scheme 15 Perfluoroalkyl induced aryl 1,2-migration of aryl $(+)$-vinylboronic pinanediol acid ester based ate complex<smiles>[R]C([R])[Bi]c1ccccc1</smiles>

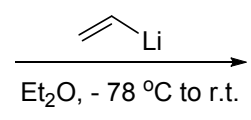

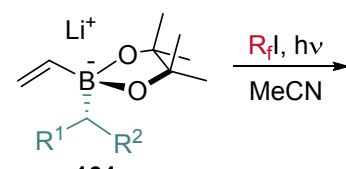

101<smiles>[R]CC(=O)C([R1])[R19]</smiles>

102<smiles>[R]C(F)=CC(=O)C([R])[R]</smiles><smiles>[R]C(CCc1ccccc1)C(=O)C=C(F)C(F)(F)F</smiles>

$\mathrm{R}^{1}=\mathrm{Me}, 47 \%$, er $=94: 6$ $\mathrm{R}^{1}=\mathrm{Et}, 46 \%$, er $=99: 1$ $\mathrm{R}^{1}=i-\operatorname{Pr}, 42 \%$, er $=99: 1$<smiles>O=C(C=C(F)[18F])CCCc1ccccc1</smiles>

Êt

$50 \%$, er $=99: 1$

图式 16 全氟烷基碘代烷诱导的手性二级烷基-烯基频那醇 嗍酸酯酸根型复合物的烷基 1,2-迁移手性

Scheme 16 Perfluoroalkyl induced alkyl 1,2-migration of enantioenriched secondary alkyl vinylboron ate complexes

\section{5 总结与展望}

发展合成含有氟烷基手性分子的新方法得到了人 们越来越多的关注, 并取得了一些重要的进展. 本文根 据反应机理将经由氟烷基自由基的手性中心构建策略 分类介绍. 这些反应均基于单电子还原的策略产生亲电 的氟烷基自由基，以实现对不饱和体系的自由基加成， 通过手性小分子催化剂、手性辅基、手性路易斯酸、手 性配体、手性磷酸的控制实现了反应对映选择性的控制. 近年来, 基于可见光光致氧化还原过程高效地产生氟烷 基自由基的方法也备受关注. 手性的烯基硼酸酯酸根型
复合物也被报道可以用来构建新的手性碳碳键. 这些反 应普遍具有高效、底物普适、选择性好等优点. 氟烷基 自由基反应也具有自身的特点和优势，例如可以直接作 用于双键，实现简单烯烃的不对称氟烷基官能团化. 然 而，采用氟烷基自由基对手性烯醇和烯胺中间体加成的 策略实现不对称氟烷基化，目前只能构建羰基 $\alpha$ 位手性 中心. 另外氟烷基自由基加成-单电子氧化过程诱导手 性烯基硼酸酯酸根型复合物的 1,2-迁移过程还存在对映 选择性不高的问题. 针对以上的局限性，基于氟烷基自 由基过程，结合其它过渡金属催化中的单电子氧化还原 过程和利用手性配体的调控，以及结合其它有机小分子 催化模式实现羰基 $\beta$ 位和 $\gamma$ 位的不对称自由基加成, 发 展普适高效、高选择性的构建手性中心的新方法，值得 人们进一步深入研究.

\section{References}

[1] (a) Furuya, T.; Kamlet, A. S.; Ritter, T. Nature 2011, 473, 470. (b) Shimizu, M.; Hiyama, T. Angew. Chem., Int. Ed. 2005, 44, 214.

[2] Lehmann, F. Arch. Exp. Pathol. Pharmakol. 1928, 130, 250.

[3] Kirsch, P. Modern Fluoroorganic Chemistry, Synthesis, Reactivity, Applications, Wiley-VCH, Weinheim, 2004.

[4] (a) Ma, J.-A.; Cahard, D. Chem. Rev. 2004, 104, 6119. (b) Ma, J.-A.; Cahard, D. Chem. Rev. 2008, 108, PR1. (c) Nie, J.; Guo, H.-C.; Cahard, D.; Ma, J.-A. Chem. Rev. 2011, 111 455.

[5] Dolbier, W. R. Chem. Rev. 1996, 96, 1557.

[6] (a) Studer, A. Angew. Chem., Int. Ed. 2012, 51, 8950. (b) Wang, X.; Zhang, Y.; Wang, J. Sci. Sin. 2012, 42, 1417.

[7] Pan, X.; Xia, H.; Wu, J. Org. Chem. Front. 2016, 3, 1163.

[8] Wang, F.; Chen, P.; Liu, G. Acc. Chem. Res. 2018, 51, 2036.

[9] (a) Fessenden, R. W.; Schuler, R. H. J. Chem. Phys. 1965, 43, 2704. (b) Krusic, P. J.; Bingham, R. C. J. Am. Chem. Soc. 1976, 98, 230.

[10] (a) Wang, S.-M.; Han, J.-B.; Zhang, C.-P.; Qin, H.-L.; Xiao, J.-C. Tetrahedron 2015, 71, 7949.

(b) Chatterjee, T.; Iqbal, N.; You, Y.; Cho, E. J. Acc. Chem. Res. 2016, 49, 2284.

(c) Wang, X.; Studer, A. Acc. Chem. Res. 2017, 50, 1712.

(d) Barata-Vallejo, S.; Cooke, M. V.; Postigo, A. ACS Catal. 2018, 8, 7287.

[11] (a) Iseki, K.; Nagai, T.; Kobayashi, Y. Tetrahedron Lett. 1993, 34, 2169.

(b) Iseki, K.; Nagai, T.; Kobayashi, Y. Tetrahedron: Asymmetry 1994, 5, 961

[12] Itoh, Y.; Mikami, K. Tetrahedron 2006, 62, 7199.

[13] Nagib, D. A.; Scott, M. E.; MacMillan, D. W. C. J. Am. Chem. Soc. 2009, 131, 10875 .

[14] Woźniak, Ł.; Murphy, J. J.; Melchiorre, P. J. Am. Chem. Soc. 2015 $137,5678$.

[15] Herrmann, A. T.; Smith, L. L.; Zakarian, A. J. Am. Chem. Soc. 2012, 134, 6976.

[16] Huo, H.; Huang, X.; Shen, X.; Harmsa, K.; Meggers, E. Synlett 2016, 27, 749.

[17] Liu, J.; Ding, W.; Zhou, Q.-Q.; Liu, D.; Lu, L.-Q.; Xiao, W.-J. Org. Lett. 2018, 20, 461.

[18] Yajima, T.; Nagano, H. Org. Lett. 2007, 9, 2513.

[19] Zhu, R.; Buchwald, S. L. Angew. Chem., Int. Ed. 2013, 52, 12655.

[20] Miller, Y.; Miao, L.; Hosseini, A. S.; Chemler, S. R. J. Am. Chem. Soc. 2012, 134, 12149.

[21] Wang, F.; Wang, D.; Wan, X.; Wu, L.; Chen, P.; Liu, G. J. Am. Chem. Soc. 2016, 138, 15547. 
[22] Wu, L.; Wang, F.; Wan, X.; Wang, D.; Chen, P.; Liu, G. J. Am. Chem. Soc. 2017, 139, 2904

[23] Fu, L.; Zhou, S.; Wan, X.; Chen, P.; Liu, G. J. Am. Chem. Soc. 2018, 140, 10965.

[24] Yu, P.; Lin, J.-S.; Li, L.; Zheng, S.-C.; Xiong, Y.-P.; Zhao, L.-J.; Tan, B.; Liu, X.-Y. Angew. Chem., Int. Ed. 2014, 53, 11890.

[25] Li, T.; Yu, P.; Du, Y.-M.; Lin, J.-S.; Zhi, Y.; Liu, X.-Y. J. Fluorine Chem. 2017, 203, 210.

[26] Lin, J.-S.; Dong, X.-Y.; Li, T.-T.; Jiang, N.-C.; Tan, B.; Liu, X.-Y. J. Am. Chem. Soc. 2016, 138, 9357.
[27] Lin, J.-S.; Wang, F.-L.; Dong, X.-Y.; He, W.-W.; Yuan, Y.; Chen, S.; Liu, X.-Y. Nat. Commun. 2017, 8, 14841

[28] Cheng, Y.-F.; Dong, X.-Y.; Gu, Q.-S.; Yu, Z.-L.; Liu X.-Y. Angew. Chem., Int. Ed. 2017, 56, 8883.

[29] Li, X.-T.; Gu, Q.-S.; Dong, X.-Y.; Meng, X.; Liu, X.-Y. Angew. Chem., Int. Ed. 2018, 57, 7668 .

[30] Kischkewitz, M.; Okamoto, K.; Mück-Lichtenfeld, C.; Studer, A. Science 2017, 355, 936.

[31] Gerleve, C.; Kischkewitz, M.; Studer, A. Angew. Chem., Int. Ed. 2018, 57, 2441.

(Li, L.; Fan, Y.) 